\title{
Maltreatment timing, HPA axis functioning, multigenic risk, and depressive symptoms in African American youth: Differential associations without moderated mediation
}

\author{
Adrienne A. VanZomeren ${ }^{1}$ (D), Jingchen Zhang ${ }^{2}$, Sun-Kyung Lee ${ }^{2}$ (D), Meredith Gunlicks-Stoessel ${ }^{3}$, Timothy Piehler ${ }^{4}$ \\ and Dante Cicchetti ${ }^{5}$ \\ ${ }^{1}$ University of Minnesota, Institute of Child Development, Institute for Translational Research, and Department of Psychiatry and Behavioral Sciences, Minneapolis, \\ Minnesota, USA; ${ }^{2}$ University of Minnesota, Family Social Science, St. Paul, Minnesota, USA; ${ }^{3}$ University of Minnesota, Department of Psychiatry and Behavioral \\ Sciences and Institute for Translational Research, Minneapolis, Minnesota, USA; ${ }^{4}$ University of Minnesota, Family Social Science and Institute for Translational \\ Research, Minneapolis, Minnesota, USA and ${ }^{5}$ University of Minnesota, Institute of Child Development and Institute for Translational Research, Minneapolis, \\ Minnesota, USA; University of Rochester, Mt. Hope Family Center, Rochester, New York
}

\begin{abstract}
Utilizing a large $(N=739)$, ancestrally homogenous sample, the current study aimed to better understand biological risk processes involved in the development of depressive symptoms in maltreated, African American children age 8-12 years. Maltreatment was independently coded from Child Protective Services records and maternal report. Self-reported depressive symptoms were attained in the context of a week-long, summer research camp. DNA was acquired from buccal cell or saliva samples and genotyped for nine polymorphisms in four hypothalamic-pituitary-adrenal (HPA)-axis-related genes: FKBP5, NR3C1, NR3C2, and CRHR1. Salivary cortisol samples were collected each morning (9 a.m.) and late afternoon (4 p.m.) throughout the week to assess HPA functioning. Results revealed that experiences of maltreatment beginning prior to age 5 were most predictive of depressive symptoms, whereas maltreatment onset after age 5 was most predictive of HPA axis dysregulation (blunted daytime cortisol patterns). Multigenic risk did not relate to HPA functioning, nor did it moderate the relationship between maltreatment and HPA activity. There was no mediation of the relationship between maltreatment and depressive symptoms by HPA dysfunction. Results are interpreted through a developmental psychopathology lens, emphasizing the principle of equifinality while carefully appraising racial differences. Implications for future research, particularly the need for longitudinal studies, and important methodological considerations are discussed.
\end{abstract}

Keywords: African American youth, depression, HPA axis, maltreatment, multigenic risk

(Received 19 August 2019; revised 7 February 2020; accepted 16 April 2020)

Child maltreatment is a potent relational pathogen whereby caregivers deprive children of basic emotional, physical, and/or psychological needs by inflicting harm and/or omitting essential care (Cicchetti \& Lynch, 1995). Extensive clinical and preclinical research over the past four decades has highlighted the pervasive, deleterious effects of maltreatment across several developmental domains (see Cicchetti \& Toth, 2015, for review), with consistent associations emerging between maltreatment and depressive symptoms (e.g., Andersen \& Teicher, 2008; Cicchetti \& Rogosch, 2001, 2014; Cicchetti, Rogosch, \& Oshri, 2011a; Kim \& Cicchetti, 2006; Manly, Kim, Rogosch, \& Cicchetti, 2001; Nanni, Uher, \& Danese, 2012; Widom, DuMont, \& Czaja, 2007).

Author for correspondence: Adrienne VanZomeren, University of Minnesota, Institute for Translational Research, 1100 South Washington Ave., Minneapolis, MN 55415; E-mail: vanz0037@umn.edu.

Cite this article: VanZomeren AA, Zhang J, Lee S-K, Gunlicks-Stoessel M, Piehler T, Cicchetti D (2020). Maltreatment timing, HPA axis functioning, multigenic risk, and depressive symptoms in African American youth: Differential associations without moderated mediation. Development and Psychopathology 32, 1838-1853. https://doi.org/ $10.1017 /$ S0954579420000589
Childhood depressive symptoms are costly to both individuals and society because they interfere with the completion of salient developmental tasks (Rice \& Miller, 1995; Wulsin \& Singal, 2003) and increase risk for chronic, recurrent psychopathology (Fombonne, Wostear, Cooper, Harrington, \& Rutter, 2001) and disability (González et al., 2010) throughout the lifespan. Even more, depressive disorders have been associated with higher prevalence of death by suicide and have been related to several chronic physical illnesses, further contributing to morbidity and mortality (Kessler, 2012). As such, it is important to understand the ways that maltreatment increases risk for depression in children to help identify early intervention targets and alleviate the tremendous impact on personal and public health.

\section{The mechanistic role of the HPA axis}

Depression is considered a stress-related disorder given that its onset and course are triggered and exacerbated by environmental stressors (Hammen, 2005; Kendler, Karkowski, \& Prescott, 1999). Consequently, it has long been speculated that the body's major 
stress-regulatory system, the hypothalamic-pituitary-adrenal (HPA) axis, plays a role in the pathogenesis of depression, particularly for maltreated individuals whose stress system has been primed to be reactive (for review, see Heim \& Binder, 2012). Findings from several lines of research over the past few decades have been used to support the theory that maltreatment uniquely predisposes for depressive symptoms through its dysregulating impact on HPA axis functioning. Previous findings include, but are not limited to, the following: (a) various forms of HPA dysfunction are present in depressed individuals (Lopez-Duran, Kovacs, \& George, 2009; Nestler et al., 2002) and prospectively predict depressive symptoms (e.g., Halligan, Herbert, Goodyer, \& Murray, 2004, 2007; Heim \& Binder, 2012; Koss, Cummings, Davies, \& Cicchetti, 2017; Saridjan et al., 2014; VrshekSchallhorn et al., 2013), but are not present in all depressed individuals (Adam et al., 2010; Birmaher et al., 1996; Feder et al., 2004), (b) reversal of both HPA dysfunction and depressive behavior in maltreated rodents can be accomplished via pharmacologic manipulation of HPA axis regulators (Weaver et al., 2004), and (c) HPA dysfunction has been observed in maltreated individuals as early as infancy (Cicchetti, Rogosch, Toth, \& Sturge-Apple, 2011b), but is most evident in depressed, maltreated individuals-both children and adults-when directly compared to depressed, nonmaltreated; maltreated, nondepressed; and non-depressed, nonmaltreated individuals (e.g., Cicchetti, Rogosch, Gunnar, \& Toth, 2010; Hart, Gunnar, \& Cicchetti, 1996; Heim et al., 2000, 2001, 2008).

Despite accumulating evidence of a mechanistic role for HPA dysfunction in the pathogenesis of depression in maltreated individuals, there are caveats and methodological constraints that complicate this theoretical conceptualization. First, because the studies comparing multiple groups of maltreated and nonmaltreated individuals with and without depression found unique neurophysiological signatures exclusively in maltreated, depressed individuals with concurrent symptoms (e.g., Cicchetti et al., 2010; Cicchetti \& Rogosch, 2014; Hart et al., 1996; Heim et al., 2000, 2008), it is possible that depressive symptoms are uniquely driving HPA dysfunction in maltreated individuals.

Secondly, recent findings have demonstrated dysregulated HPA stress responses for maltreated young adults (males) independent of current depressive symptoms (Ouellet-Morin et al., 2019). Thus, it is possible that other mechanisms and/or moderators excluded from previous studies better account for the increased rate of depressive symptoms in maltreated individuals. Because cortisol reactivity is just one aspect of HPA functioning, results from Ouellet-Morin et al. (2019) may further suggest that different components of HPA activity (e.g., reactivity to stress vs. diurnal patterns, daily cortisol output, etc.) have differential associations with depressive symptoms and represent underlying functional differences. Third, very few studies have examined HPA function as a mediator of the maltreatment-depression link. For the studies that have examined mediation (e.g., Halligan, Herbert, Goodyer, \& Murray, 2007), measures have not specifically included maltreatment. Better specified mediation models are needed to clarify biological risk processes, which may differ for different forms of adversity (Koss \& Gunnar, 2018).

Finally, and most importantly, there is a paucity of research focused exclusively on risk processes for depression and other stress-related diseases in African Americans, despite greater prevalence (Warnecke et al., 2008), especially for severe and disabling depression (Williams et al., 2007), among African Americans. Notably, different risk processes for African Americans (vs. Caucasians) have been found for many other complex physical and neurocognitive conditions (Bertrand, Bethea, AdamsCampbell, Rosenberg, \& Palmer, 2016; Clark et al., 2018; O'Neal et al., 2017). Moreover, economic disadvantage, in the context of greater exposure to other potent social stressors such as racial discrimination, contributes to increased rates of depressive disorders in African American youth (Brody et al., 2006). Thus, higher prevalence and disproportionate aggregation of risk factors/stressors warrant deliberate focus on African American risk processes to determine if alleged mechanisms operate similarly in this distinct group, so that appropriate interventions can be generated. Although longitudinal studies are best suited to disentangle this complex developmental picture and cross-sectional studies cannot help clarify sequencing effects, examining HPA functioning as a mediator in the current study is a first step toward better understanding the developmental process for African Americans, overall, and would serve as proof of concept to support future investigation.

\section{Genetic moderation}

If HPA axis dysregulation facilitates depression in maltreated individuals, purportedly as a result of frequent or chronic activation of the HPA axis in the context of the profound stress of maltreatment experiences, then genetic factors that govern whether and to what extent the HPA axis will respond to the stress of maltreatment should emerge as a significant moderator of the relationship between maltreatment and HPA function. As a first step in validating this conceptual model, several researchers have investigated the contribution of variation in genes that govern the stress response to depressive symptoms or depressive endophenotypes in the context of child maltreatment (or other early life stress) and have found significant associations (e.g., Binder et al., 2004; Bogdan, Williamson, \& Hariri, 2012; Bradley et al., 2008; Cicchetti et al., 2011a; Cicchetti \& Rogosch, 2014; Di Iorio et al., 2017; Feurer et al., 2017; Liu et al., 2006; Pagliaccio et al., 2014; Polanczyk et al., 2009; Starr \& Huang, 2019; Tyrka et al., 2009; Zannas \& Binder, 2014). Among the HPA-related genes, four are particularly common given documented relationships with HPA axis dysregulation, depressive symptoms, and/or depression endophenotypes: FK506 binding protein 5 (FKBP5), corticotropin releasing hormone receptor 1 (CRHR1), nuclear receptor subfamily 3, group C, member 1 (NR3C1), and nuclear receptor subfamily 3 , group $\mathrm{C}$, member 2 (NR3C2).

More recently, FKBP5, CRHR1, NR3C1, and NR3C2 have been examined together in a multigenic index (vs. individual single nucleotide polymorphism (SNP) or haplotype analysis) in an effort to better capture the complicated nature of development and to increase statistical power. Pagliaccio et al. (2014) created an HPA-related multigenic risk index with ten SNPs across these four HPA genes and found increased cortisol levels in predominately Caucasian, preschool-aged children with higher multigenic risk. The interaction of multigenic risk scores and early life trauma further predicted differences in brain structure, with hypothesized implications for vulnerability to depressive symptoms. Starr and Huang (2019) used the same multigenic index to examine its moderation of the relationship between childhood adversity and depressive symptoms (rather than depression endophenotypes) in primarily Caucasian adolescents. Results extended earlier findings by Feurer et al. (2017), such that youth with higher HPA-related multigenic risk had higher depressive 
symptoms and stronger associations between interpersonally based early life stress and depressive symptoms (Starr \& Huang, 2019).

While these recent HPA-related multigenic risk studies add greatly to the literature as they better represent a theoretically relevant biological system implicated as a mechanism by which early stress becomes biologically embedded and affects mental health, the findings continue to offer an incomplete picture. That is, most studies examined multigenic moderation of purported endophenotypes of depressive symptoms (i.e., structural and functional brain changes) rather than directly examining multigenic moderation of HPA function. Furthermore, none of the studies exclusively examined child maltreatment; rather, adversity was broadly conceptualized.

Most significantly, the extant literature under-represents African Americans, especially in genetic association studies (Odgerel, Talati, Hamilton, Levinson, \& Weissman, 2013). Existing genetic studies that have included African Americans have only examined individual SNP/haplotypes in association with depressive outcomes, rather than using a more robust measure (multigenic risk index). Thus, our understanding of whether multigenic risk indices generalize to African Americans is gravely undeveloped. Moreover, there is lack of coherence among these previous SNP/haplotype studies' categorization of risk both among African American samples and relative to predominately Caucasian samples (see Bradley et al., 2008; Cicchetti et al., 2011a; Cicchetti \& Rogosch, 2014; Feurer et al., 2017; Pagliaccio et al., 2014; Polanczyk et al., 2009 for differences in major/ minor allele classification, inconsistency in reporting the A/G vs. C/T base pairing, and differences in labeling of CRHR1 TAT haplotypes as "protective" vs. "risk"). It is therefore imperative to focus exclusively on African Americans to better characterize developmental risk processes for this distinct and underrepresented population, particularly given existing stress-related health disparities. Because our sample is ancestrally homogeneous, we can properly control for population stratification, thereby increasing clarity of our results.

To our knowledge, no studies to date have examined multigenic variation, early stress in the form of maltreatment, HPA axis functioning, and depressive symptoms together in one model, for any race. More importantly, for the previous studies that have tested associations between multigenic risk and HPA activity (e.g., Pagliaccio et al., 2014; Starr, Dienes, Li, \& Shaw, 2019), depressive symptoms were not included. Without including all variables in one model, the mechanistic role of HPA axis functioning will continue to be unclear, and results will continue to be piecemeal. Thus, building a moderated mediation model in the current study will help clarify the nature of these relationships in ways that previous studies could not, while focusing specifically on African Americans. Optimized measures of both genetic risk (multigenic scores) and environmental risk (prospective, confirmed reports of child maltreatment), as well as considering maltreatment timing effects, will enhance specificity of findings, expanding our knowledge of the biological salience of different timing windows and associated developmental pathways for African American children.

\section{The current study}

\section{Developmental timing}

Previous research suggests that children maltreated during or prior to the preschool years are most vulnerable to developing depressive symptoms (e.g., Cicchetti et al., 2010; Cicchetti \& Rogosch, 2014; Hart, Gunnar, \& Cicchetti, 1995, 1996; Kaplow \& Widom, 2007; Keiley, Howe, Dodge, Bates, \& Pettit, 2001; Manly et al., 2001). Kaplow and Widom (2007) examined the predictive utility of different classifications of maltreatment timing (i.e., continuous, dichotomous, and developmental), and found that both dichotomous (age 0-5 vs. age 6-11) and developmental (infancy, preschool, early school, and school age) classifications predicted depressive symptoms. Specifically, age 0-5, infancy (age 0-2), and preschool (age 3-5) categorizations all predicted higher depressive symptoms in maltreated adults. These results informed our decision to include children whose first experience of maltreatment occurred during or before preschool in our early-onset maltreatment group.

Stress-related neural systems that are involved in HPA function undergo drastic construction, and are particularly sensitive to experiences of stress, during the first years of life (Pechtel \& Pizzagalli, 2011; Thompson \& Nelson, 2001), potentially making the early postnatal period a salient and sensitive period for shaping stress responses and influencing stress-related disorders such as depression. While earlier periods prior to age five (i.e., ages 1-2 years) have been proposed as a possible inflection point for the impact of early adversity on HPA function (for review, see Kuhlman, Chiang, Horn, \& Bower, 2017), we opted against testing earlier timing categorization to stay consistent with the previous maltreatment timing-based studies we aimed to extend (Cicchetti et al., 2010, 2011a, 2014; Pagliaccio et al., 2014).

\section{Hypotheses}

1. Children whose maltreatment onset began before age five (i.e., "early-onset maltreated children") will have higher levels of depressive symptoms than children whose maltreatment onset began during later developmental periods (i.e., "lateonset maltreated children") and nonmaltreated children.

2. Early-onset maltreated children will have less change (i.e., blunted diurnal pattern) in cortisol from morning to evening compared to later onset and nonmaltreated groups, particularly for early-onset maltreated children with higher depressive symptoms.

3. The relationship between early-onset maltreatment and depressive symptoms will be mediated by cortisol function, such that the indirect effects of early-onset maltreatment on cortisol and cortisol on depressive symptoms will better explain the observed relationship between early-onset maltreatment and depressive symptoms.

4. Genetic risk will moderate the impact of maltreatment on cortisol functioning such that early-onset maltreated children with the highest genetic risk scores will have the least amount of change in cortisol across the day and the highest level of depressive symptoms.

\section{Method}

\section{Participants}

The current study focuses on African American children (age 812 years; $M=10.37, S D=1.31$ ) who attended a week-long summer camp for low-income youth between the years 2004-2012. Within the camp context, genetic, HPA, and depressive symptom data were collected from maltreated ( $n=373 ; 47 \%$ female) and nonmaltreated ( $n=366 ; 53 \%$ female) youth.

To allow study of maltreatment above and beyond effects of poverty, all children were from predominantly low-income, 
Table 1. Demographic characteristics

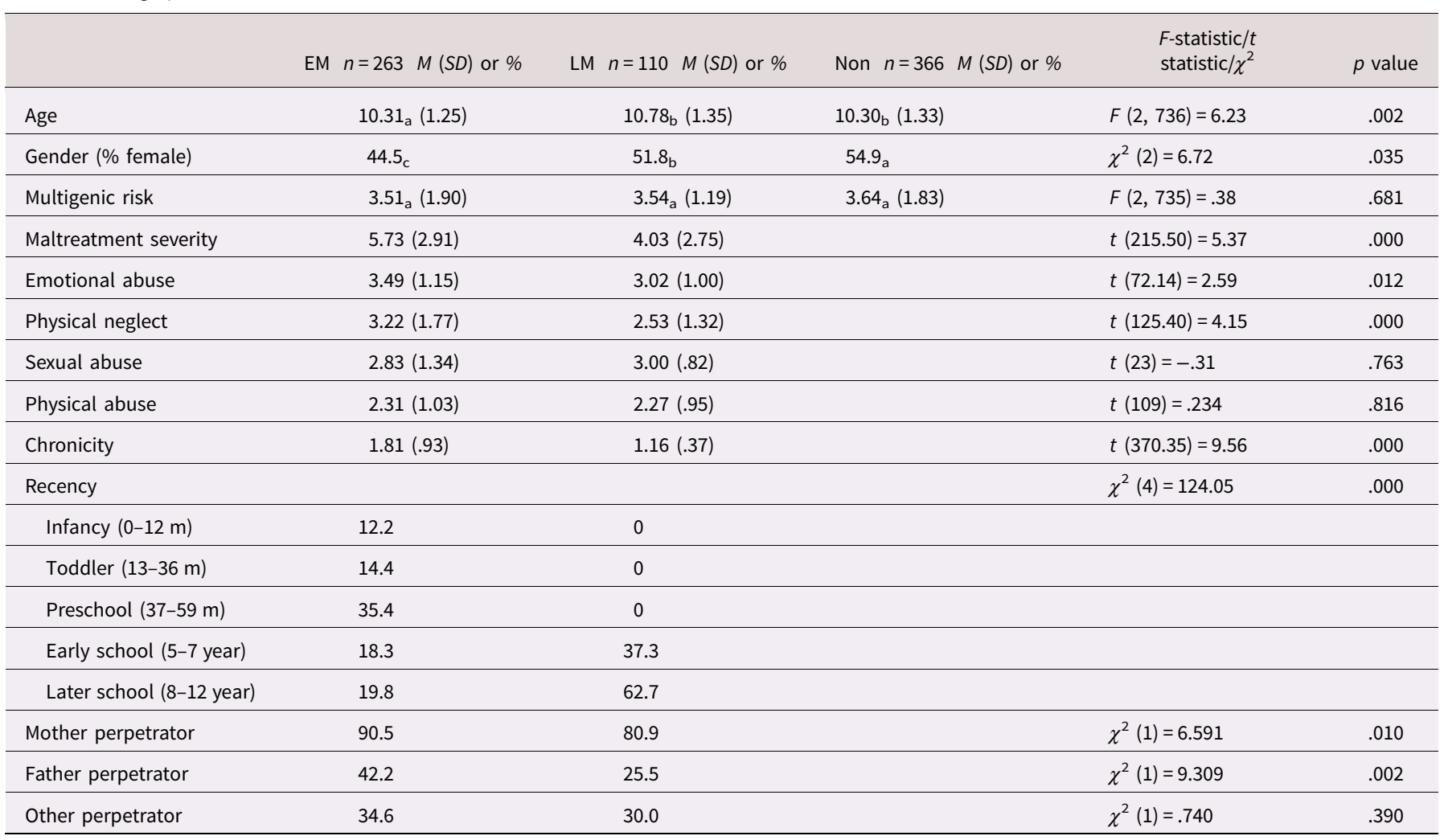

Note: $\mathrm{EM}=$ early-onset maltreated; $\mathrm{LM}=$ late-onset maltreated; Non = nonmaltreated. Severity= seriousness of the maltreatment act, including potential for harm to the child; summed across subtypes $(\max =20)$. Chronicity = number of developmental periods (infancy (0-12 months), toddler (13-36 months), preschool (37-59 months), early school (5-7 years), later school (8-12 years) during which maltreatment occurred $(\max =5)$. Recency = developmental period during which maltreatment most recently occurred. Values with subscript a are significantly higher than values with subscript $b$, and values with subscript $b$ are significantly higher than values with subscript $c$.

disadvantaged families (90\% received Temporary Assistance for Needy Families; TANF). To test for timing effects, maltreatment groups were subdivided into early-onset maltreated (maltreatment onset before age $5 ; n=263$ ), late-onset maltreated (maltreatment onset at age 5 and beyond; $n=110)$, and nonmaltreated $(n=$ 366) groups, consistent with previous studies finding higher rates of diurnal flattening and/or depressive symptoms in children whose maltreatment onset occurred during the preschool years or earlier (e.g., Cicchetti et al., 2010; Cicchetti \& Rogosch, 2014; Hart et al., 1996; Kaplow \& Widom, 2007; Keiley et al., 2001; Manly et al., 2001). Maltreatment groups differed by gender and age; thus, both variables were added to the structural model to control for potential confounding effects. Table 1 lists demographic characteristics of each maltreatment group.

\section{Procedure}

\section{Family recruitment}

All study procedures were approved by the University of Rochester Institutional Review Board. Families were recruited with the assistance of a Department of Human Services (DHS) liaison. The DHS liaison contacted a random sample of identified maltreating families to explain purposes and procedures involved with the research study. Interested parents signed consent for the liaison to release their contact information to the research team and to allow for comprehensive examination of their DHS record files. Nonmaltreated children were recruited, also via DHS liaison, from families receiving TANF, to create a demographically matched comparison group.

\section{Data collection}

Parental consent and child assent were acquired prior to participation. All families were free to withdraw from participation in the study at any time without penalty. Children attended the week-long, research-based summer camp program $7 \mathrm{hr} /$ day for five consecutive days. Children were divided into groups of eight (composed of both maltreated and nonmaltreated children of the same age and gender). Each group was led by three trained camp counselors unaware of maltreatment status and hypotheses of the study (see Cicchetti \& Manly, 1990, for detailed descriptions of camp procedures). Trained research assistants, also unaware of maltreatment status and study hypotheses, collected data from children during the week. Along with research activities, children participated in a variety of recreational activities at the camp. Clinical support by licensed providers was available for any imminent concerns regarding a child's safety.

\section{Measures}

\section{Demographics}

Parents (typically mothers) reported on child demographic variables. Age was determined based on parent-reported birth date relative to the child's first day of study enrollment. Gender was reported by the parent and coded into a dichotomous variable ( $1=$ Male, $0=$ Female). Race/ethnicity was reported by parent 
and also assessed using a SNP panel of 106 ancestry-informative genetic markers (AIMS), which was used to classify children into African, European, or Native American descent. The inclusion of children into the current study's African American sample was ultimately based on the proportion of African ancestry a child possessed (i.e., African AIMS scores $\geq 0.6$ ); however, for a majority of children (97\%), ancestral characterization overlapped with parent-reported race/ethnicity.

\section{Maltreatment}

Maltreatment information in DHS records was coded by trained members of the research team using the Maltreatment Classification System (MCS; Barnett, Manly, \& Cicchetti, 1993; Cicchetti \& Barnett, 1991). The MCS has been shown to be a highly reliable and valid method of classifying maltreatment experiences (Bolger, Patterson, \& Kupersmidt, 1998; English et al., 2005). For the current study, reliabilities ( $\kappa s)$ for maltreatment timing and type ranged from 0.90 to 1.00 . Mothers in the nonmaltreatment group underwent semi-structured clinical interview (Cicchetti, Toth, \& Manly, 2003) to further verify absence of maltreatment. Maltreatment was dummy coded into early or late onset, with nonmaltreated children serving as the reference group. Of note, our categorization of maltreatment onset did not create mutually exclusive groups. In fact, many early-onset maltreated children continued to experience maltreatment throughout several developmental periods (see Table 1 for other features of maltreatment coinciding with early and late onset).

\section{Depressive symptoms}

There is precedent for the exclusive use of self-reported depressive symptoms, given the difficulty for outside observers to accurately assess internal states of others and the considerable disagreement between children's self-report and other informants' report (De Los Reyes \& Kazdin, 2005; Reynold, Anderson, \& Bartell, 1985). For this reason, we used a well-established and both internally and externally validated measure of self-reported depressive symptoms in the current study.

CDI. The Children's Depression Inventory (CDI; Kovacs, 1982, 1992) is a 27-item self-report measure of various depressive symptoms that school-age children report experiencing over the past two weeks. Internal consistency for the total scale has been reported from 0.71 to 0.89 (Kovacs, 1982, 1992). Symptom areas include negative mood (sadness, tearfulness, worry), interpersonal problems (problems with social interaction), ineffectiveness (negative evaluation of performance), anhedonia (loss of interest, low energy), and negative self-esteem (self-dislike, feeling of being unlovable). Each item is rated on a 3-point, Likert-type scale of 0 to 2, with 2 indicating the highest level of the symptom. Overall depression scores of 19 and above reflect clinically significant concerns, though cut-off scores as low as 11 have been suggested for samples in which the prevalence of depression is likely to be higher (Kovacs, 1982, 1992). Total scores for the current sample ranged from 0 to $48(M=7.57 ; S D=6.94)$. A minority $(8.14 \% ; n=59)$ of children in the current sample met or exceeded the more stringent clinical cutoff, while $25.1 \%$ had scores of 11 or above. Cronbach alpha was .854 .

\section{HPA functioning}

Saliva samples were obtained each morning upon arrival to camp at 9 a.m. and each afternoon at 4 p.m. to provide daily cortisol production patterns across the camp week. A majority (97\%) of children had at least three samples (of five total) for each time point. Camp staff ensured that sample collection occurred consistently at least $1 \mathrm{hr}$ after awakening and that food and drink were not consumed for at least $30 \mathrm{~min}$ prior to saliva collection. Following collection, saliva samples were immediately stored at $-40{ }^{\circ} \mathrm{C}$. Samples were later shipped overnight for assaying in duplicate by Salimetrics Laboratories (State College, PA) using an enzyme immunoassay (with assay sensitivity parameters ranging from $0.0007 \mu \mathrm{g} / \mathrm{dl}$ to $1.8 \mu \mathrm{g} / \mathrm{dl}$ with $5 \%$ and $10 \%$ intra- and inter-assay coefficient variation, respectively). Cortisol production across the daytime period as measured in the current study proxies the diurnal regulatory capacity of the HPA axis, though it is not equivalent to the diurnal rhythm. Measuring the full diurnal rhythm requires collecting cortisol samples immediately upon awakening and at bedtime; these home collection procedures were not possible for this study. Mean raw cortisol values (in $\mu \mathrm{g} / \mathrm{dl}$ ) across camp days were as follows: $M$ morning $=0.20$, $S D=0.11 ; M$ afternoon $=0.10, S D=0.05$.

A difference score was created to index pattern of change in cortisol from morning to late afternoon, ultimately offering a cortisol slope (change) value. To create the difference score/slope, the mean morning raw score value was subtracted from the mean afternoon raw score value. In the event of missing data across the five days for each time point, available values were used to calculate the average. If a child was missing all values from Monday through Friday, a difference score was not calculated, and data were considered missing. Negative (lower) cortisol difference score/slope values represent a greater change from morning to evening, which reflects more typical cortisol production patterns whereby cortisol levels decline progressively over the course of the day. Higher cortisol difference score/slope values closer to zero thus represent a "flattening" of the typical morning-to-afternoon pattern. Cortisol difference scores were skewed and kurtotic (Skewness $=-2.07$, Kurtosis =9.22); however, once outliers $\geq 3 S D(n=11)$ were removed (treated as missing), skewness and kurtosis were at acceptable levels $(M$ difference score $=-0.09, S D=0.08$; range $=$ $-0.37-0.15$; Skewness $=-0.92$, Kurtosis $=1.27$ ).

\section{Genetic risk}

DNA collection, extraction, and genotyping. Oragene collection kits (DNA Genoteck Inc., Ontario, Canada) and/or Epicentre Catch-All Collection Swabs were used to obtain saliva and/or buccal swab DNA samples, respectively. For buccal cells, DNA was extracted and prepared for polymerase chain reaction (PCR) amplification using the Epicentre BuccalAmp DNA Extraction Kit (Epicentre, Cat. No. BQ090155C). For saliva, DNA was purified from $0.5 \mathrm{ml}$ of Oragene-DNA solution using the DNA genotek protocol for manual sample purification using prepIT-L2P. Sample concentrations were quantified using the Quant-iT PicoGreen dsDNA Assay Kit (P7589, Invitrogen). Applied Biosystems Custom Taqman SNP Genotyping Assays were used for SNP genotyping. TaqMan procedures were performed on several gene variants. Genotypes were identified and sequenced with the BeckmanCoulter CEQ8000 semiautomated fluorescent sequencing system, which utilizes Fragment Analysis Application and associated software. In addition, human DNA control samples purchased from Coriell Cell Repositories were used for each genotype. Samples that were not able to be genotyped to a $95 \%$ or greater confidence level were repeated under the same procedures up to four times.

Multigenic risk index. Nine variants across four stress-system genes (CRHR1, FKBP5, NR3C1, and NR3C2) were used to create 
Table 2. Genetic coding summary with genotype frequencies by maltreatment group

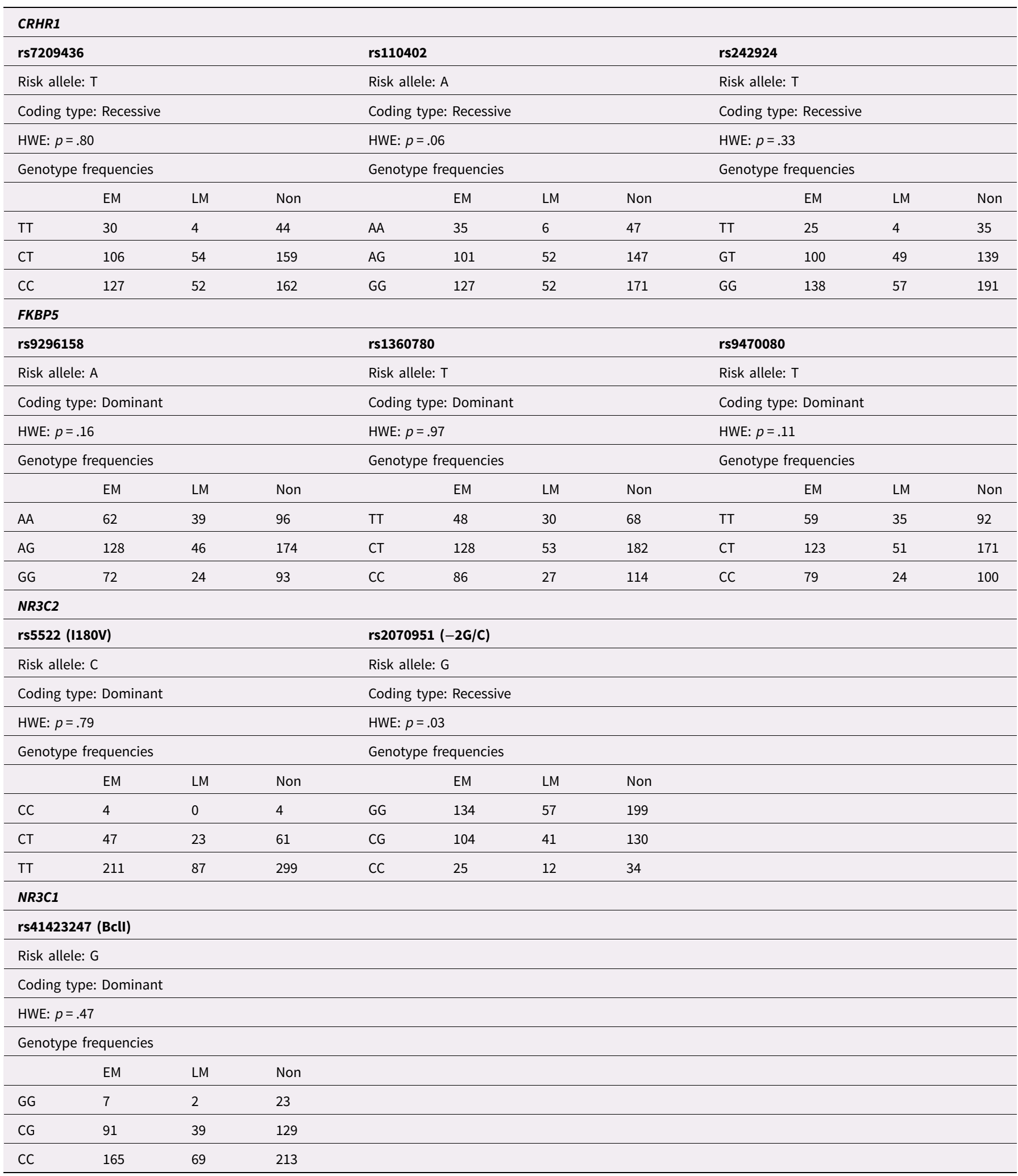

Note: $\mathrm{EM}$ = early-onset maltreated; LM = late-onset maltreated; Non = nonmaltreated; HWE = Hardy-Weinberg equilibrium.

a multigenic index of risk. All genes and SNPs included in the multigenic risk index were chosen given their documented relationship to HPA axis functioning and/or interaction with maltreatment or other early adversity to predict depression or depression-related phenotypes, in accordance with previous studies (e.g., Binder et al., 2004; Cicchetti et al., 2011a; Cicchetti \& Rogosch, 2014; Dackis, Rogosch, Oshri, \& Cicchetti, 2012; Feurer et al., 2017; Pagliaccio et al., 2014; Starr \& Huang, 2019). 
Table 3. Associations of single nucleotide polymorphism (SNPs) and polygenic risk score with maltreatment, diurnal slope, and Children's Depression Inventory (CDI)

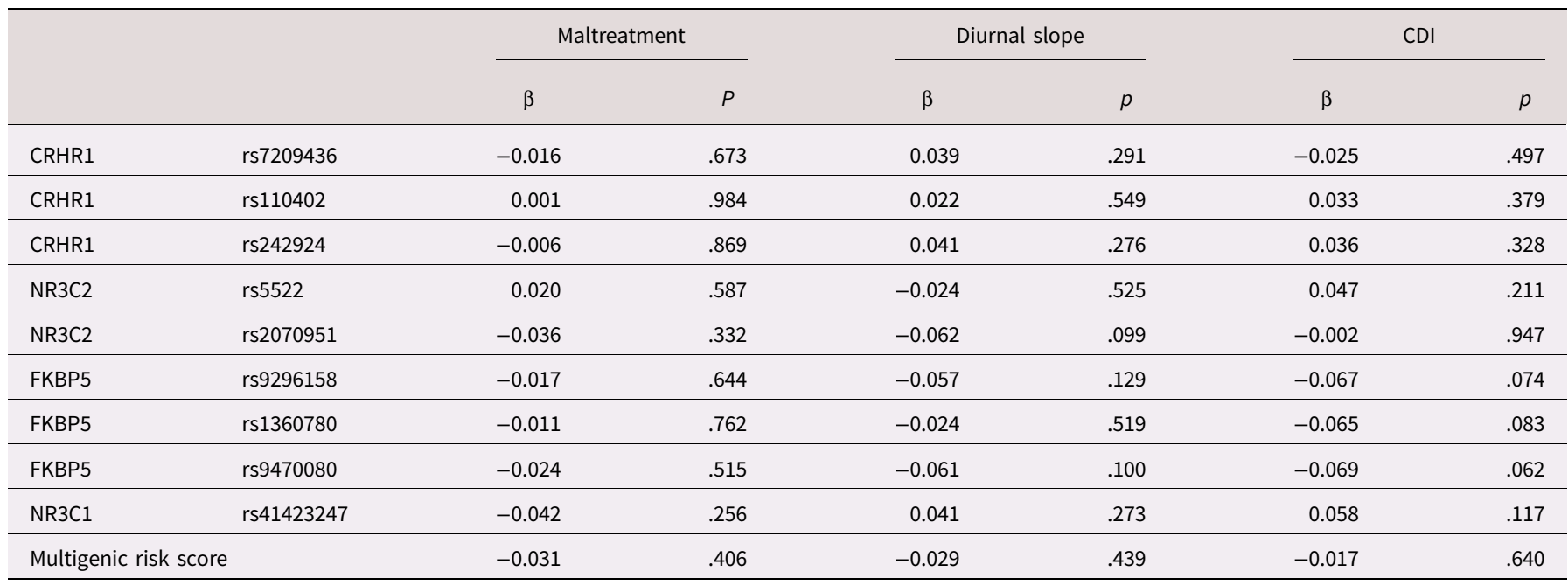

Note: Values represent the regression coefficient for each SNP or multigenic risk score from separate regressions with maltreatment, diurnal slope, and CDI variables.

Optimally, all selected SNPs would have overlapped with those used by Pagliaccio et al. (2014) and Starr and Huang (2019) in an effort to replicate and directly extend their findings with primarily Caucasian samples to African Americans. However, five of the nine SNPs included in the current study (i.e., CRHR1: rs7209436, rs242924; FKBP5: rs9296158, rs9470080; and NR3C2: rs2070951) did not overlap given the archival nature of the data. Six of the nine SNPs completely overlapped with those used by Feurer et al. (2017). Two remaining SNPs (FKBP5 rs9296158 and rs9470080) have not been previously included in multigenic risk indices to our knowledge, but individual SNP analyses have supported their inclusion given relevance to HPA functioning (impaired negative feedback) in adults (Binder et al., 2004) and demonstrated association with maltreated adult women's depression symptoms (Dackis et al., 2012).

Among all nine SNPs, only a subset has been studied exclusively in African American samples, and, even then, have produced discrepant results. In these instances (i.e., all six CRHR1 and all three FKBP5 SNPs), a decision to follow coding of the samples that utilized African Americans and incorporated measures of maltreatment, specifically, was made (e.g., Binder et al., 2008; Cicchetti et al., 2011a; Dackis et al., 2012). For the other SNPs (NR3C1 and NR3C2), coding based on Caucasian samples (Bogdan et al., 2012; Feurer et al., 2017; Wüst et al., 2004) was applied, though different models of coding were explored to account for uncertainty. Genotypes were coded as " 1 " or " 0 ," depending on identified potency of the risk allele (see Table 2). Specifically, a recessive model was adopted for coding CRHR1 rs7209436, rs110402 and rs242924 as well as NR3C2 rs2070951, such that individuals homozygous for the identified risk allele were coded as "1," while individuals heterozygous for risk were grouped with those homozygous for the nonrisk allele and coded as "0." A dominant model was used for coding the remaining SNPs (i.e., NR3C2 rs5522; NR3C1 rs41423247; and FKBP5 rs9296158, rs1360780, and rs9470080), such that individuals with any risk allele were coded as " 1 " while those homozygous for the non-risk allele were coded as " 0 ."

Number of risk genotypes across all nine SNPs were summed $(M=3.58, S D=1.78$, range $=0-9)$ to create a multigenic risk score, where higher scores reflected higher number of risk genotypes previously associated with HPA axis dysregulation and/or other depression-related outcomes. If a child had four or fewer genotypes missing across the nine SNPs, a prorated risk score was calculated by counting the number of risk genotypes and dividing by the total number of available data points to determine percentage of risk and applying that percentage to nine to determine overall risk score $(1.89 \%$ of the sample used this method).

Multigenic risk scores were mean-centered to remove multi-colinearity. For each SNP, Hardy-Weinberg equilibrium (HWE) was calculated. Deviation from HWE was observed for rs2070951. The magnitude of the $p$ value for this SNP suggests that this deviation is not of substantial concern (see Turner et al., 2011), obviating the need to exclude or explore this subgroup in further analyses. All other SNPs were in HWE. Linkage disequilibrium for the SNPs used in our multigenic risk index ranged from -.012 to 0.908 , with higher correlations existing for SNPs within CRHR1 and FKBP5. While there has been concern that the predictive accuracy of multigenic risk scores decreases among linked genotypes (Vilhjálmsson et al., 2015), other studies have demonstrated utility of using co-inherited SNPs (i.e., Feurer et al., 2017; Pagliaccio et al., 2014). Neither individual SNPs nor the overall multigenic risk score were related to maltreatment status, demonstrating a lack of gene-environment correlation (see Table 3). Furthermore, neither individual SNPs nor multigenic risk were significantly associated with diurnal cortisol or depressive symptoms, suggesting that this particular set of SNPs is neither acting in isolation nor in combination to predict HPA function or depressive symptoms in our sample of African American youth.

\section{Results}

\section{Data analytic plan}

The primary analyses for the current investigation included structural equation modeling computed in Mplus 8 (Muthén \& Muthén, 1998-2017), linkage disequilibrium testing using $\mathrm{R}$ (Version 1.2.5001), and descriptive analyses conducted in SPSS 23.0. To assess the model fit, the comparative fit index (CFI; 
Table 4. Means, standard deviations, and bivariate correlations of study variables

\begin{tabular}{|c|c|c|c|c|c|c|c|}
\hline & 1 & 2 & 3 & 4 & 5 & 6 & 7 \\
\hline 1. EM & - & & & & & & \\
\hline 2. LM & $-.311^{\star \star}$ & - & & & & & \\
\hline 3. Gene risk & -.026 & -.008 & - & & & & \\
\hline 4. Cort change & -.017 & $.086^{\star}$ & -.029 & - & & & \\
\hline 5. CDI & $.114^{\star \star}$ & .002 & -.017 & -.012 & - & & \\
\hline 6. Age & -.037 & $.129^{\star \star}$ & -.049 & $-.098^{\star \star}$ & -.014 & - & \\
\hline 7. Female & $.093^{\star}$ & -.009 & .009 & .031 & $.081^{\star}$ & -.037 & - \\
\hline$M$ & - & - & 3.576 & -.088 & 7.570 & 10.375 & .490 \\
\hline$S D$ & - & - & 1.776 & .077 & 6.943 & 1.315 & .500 \\
\hline
\end{tabular}

Note: $\mathrm{EM}=$ early-onset maltreated; $\mathrm{LM}=$ late-onset maltreated; Gene risk = multigenic risk score; Cort change = cortisol change across the day; $\mathrm{CDI}=\mathrm{Children's} \mathrm{Depression} \mathrm{Inventory} \mathrm{(total} \mathrm{raw}$ scores). ${ }^{\star} p \leq .05,{ }^{\star \star} p \leq .01$.

above 0.95), standardized root-mean-square residual (SRMR; below 0.08) and root mean squared error of approximation (RMSEA; below 0.06) were examined ( $\mathrm{Hu} \&$ Bentler, 1999). Self-reported depressive symptoms were used as the dependent variable in a structural equation model with maltreatment status (early onset vs. late onset vs. non) as the dummy-coded independent variable, cortisol values as a mediator of the effect of maltreatment on depressive symptoms, and multigenic risk as a moderator of the impact of maltreatment on cortisol. Gender and age were added to the structural model to control for confounding effects given the unequal distribution of gender and age across maltreatment groups. In accordance with recommendations by Dick et al. (2015), the interaction effects of maltreatment by covariates (i.e., child age and child gender) and multigenic risk by covariates were also examined.

Follow-up analyses were conducted to help understand the nature of original findings, and to compare our findings to previous studies. First, differences in mean morning and mean afternoon cortisol values among groups were tested to understand the nature of the cortisol flattening results. Next, results were examined with regard to severity of depressive symptoms. Chronicity and recency of maltreatment and their overlap with early and late onset of maltreatment were also examined. Additionally, given differences in the literature regarding approach to coding genetic risk, and lack of precedent for coding some African American genotypes, six additional types of coding schemes were tested to examine the effect of different coding approaches on the original results. Finally, because most previous studies finding significant genetic moderation have tested the maltreatment-depression pathway rather than maltreatment-cortisol pathway, we probed this interaction for comparison.

\section{Descriptive statistics}

Bivariate correlations (Table 4) showed that child self-reported depressive symptoms were significantly correlated with earlyonset maltreatment. Specifically, children whose maltreatment onset began early reported higher levels of depressive symptoms than nonmaltreated children. Child age was negatively associated with diurnal cortisol, with older children showing greater change from morning to evening (i.e., steeper slopes) than younger children. Child gender was significantly associated with depressive symptoms such that girls reported higher levels of depressive symptoms than boys.

\section{Structural model}

The proposed structural model demonstrated good model fit including child gender and age as covariates $\left(\chi^{2}(3)=2.352\right.$, $p=.503$, RMSEA $=.000, \quad$ SRMR $=.008, \quad \mathrm{CFI}=1.000)$. Results for the structural model are depicted in Figure 1, which labels significant (solid lines) and non-significant paths (dashed lines) with their respective standardized coefficients. Overall, the model explained $2.2 \%$ of the variability in cortisol difference scores and $2.0 \%$ of variability in self-reported depressive symptoms. The interaction effects of maltreatment by covariates (i.e., child age and child gender) and multigenic risk by covariates were not significant and their inclusion greatly reduced model fit; therefore, those interaction variables were removed from the final structural model. Specific path findings are presented below.

\section{Cortisol change}

A main effect of maltreatment on cortisol was found such that later onset maltreated children demonstrated a higher (i.e., more positive; thus, closer to zero) cortisol difference score value $(B=.023, S E=.008, \beta=.105, p=.007)$, meaning they evinced less change in cortisol values between morning to afternoon, relative to nonmaltreated children. When a separate model with early-onset maltreated children as the reference group was run, late-onset maltreated children also had higher cortisol difference values than early-onset maltreated children $(B=.021, S E=.009$, $\beta=.021, p=.016$ ). Early-onset maltreated children did not differ from nonmaltreated children in their cortisol difference value $(p=.802)$. There was also a main effect of child age on cortisol difference values such that older children had more negative difference score values (i.e., greater change from morning to evening) than younger children $(B=-.007, S E=.002, \beta=-.111$, $p=.003)$.

\section{Depressive symptoms}

A main effect of maltreatment on self-reported depressive symptoms was found such that early-onset maltreated children 


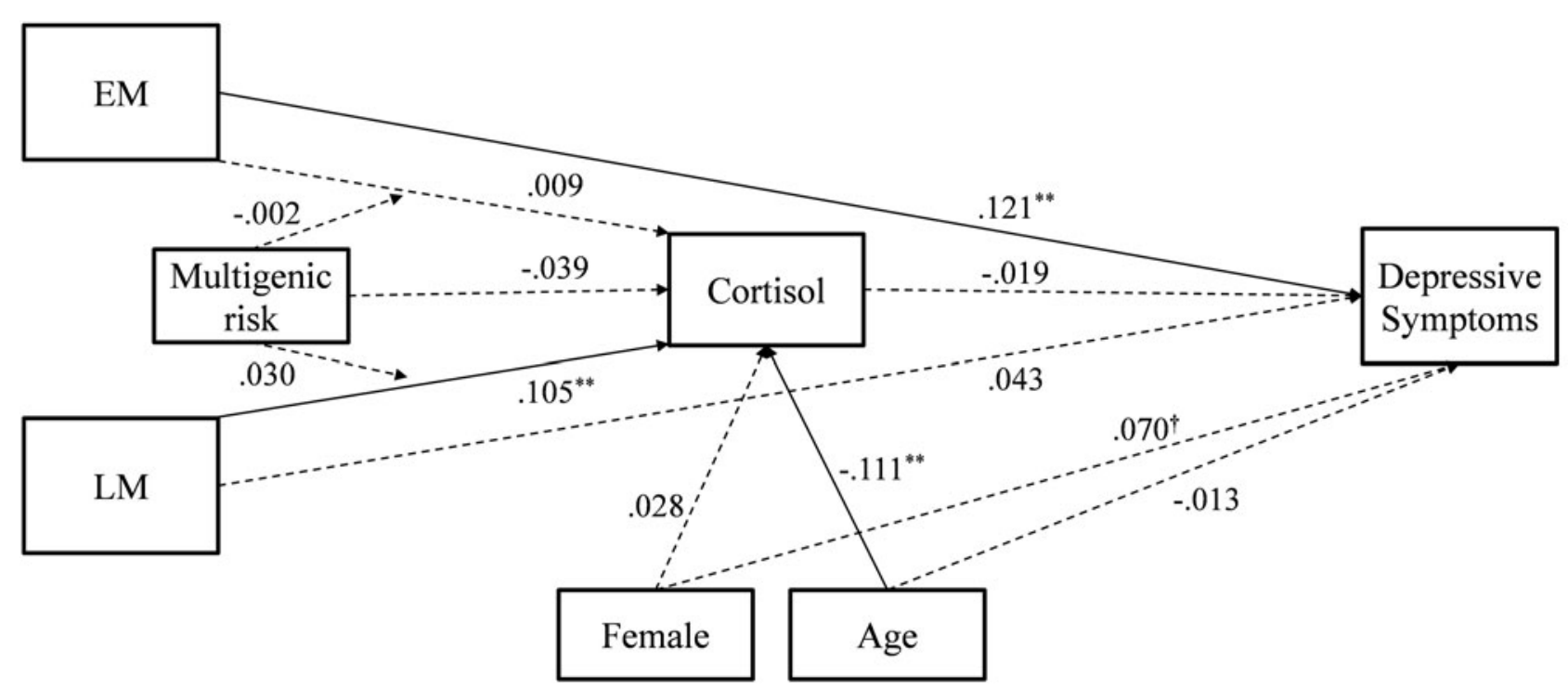

Figure 1. Structural equation model of maltreatment as a predictor of self-reported depressive symptoms, controlling for gender and age. Note: EM = early-onset maltreated; $L M=$ late-onset maltreated; Multigenic risk = multigenic risk score; cortisol = cortisol change across the day (difference score); Significant (solid lines) and non-significant paths (dashed lines) are labeled with their respective standardized coefficients. Fit indices: $\chi^{2}(3)=2.352 ; \mathrm{RMSEA}=.000, \mathrm{CFI}=1.00$, SRMR $=.008$. $p<.07,{ }^{\star} p<.05,{ }^{\star \star} p<.01,{ }^{\star \star \star} p<.001$.

Figure 2. Mean differences in depressive symptoms by maltreatment status. Note: $\mathrm{EM}=$ early-onset maltreated; $L M=$ late-onset maltreated; Non =nonmaltreated; $\quad$ CDI = Children's Depression Inventory (total raw scores). Error bars show $1 S D$.

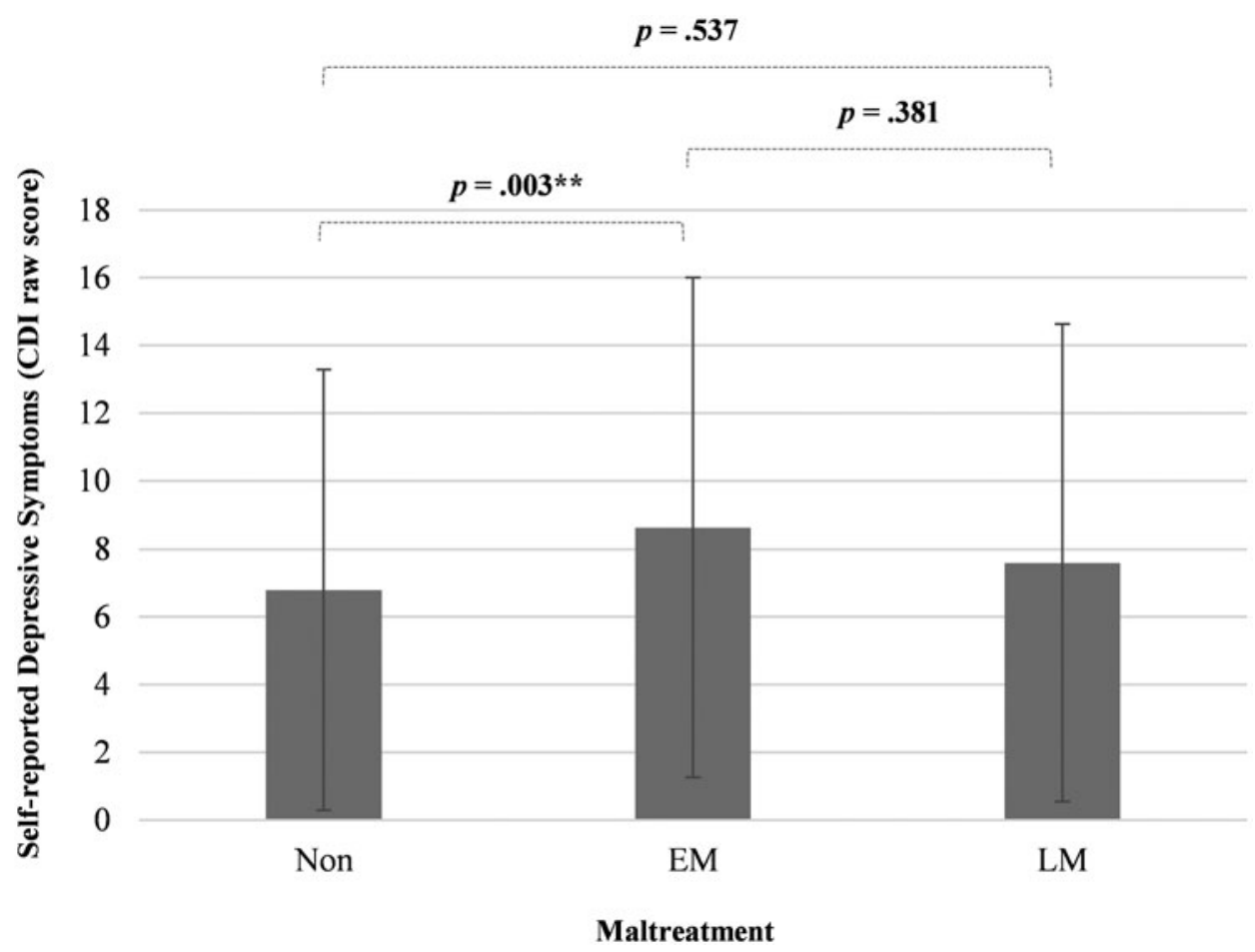

reported more depressive symptoms than nonmaltreated children $(B=1.757, S E=.565, \beta=.121, p=.002)$. There were no differences between late-onset and nonmaltreated children $(B=.846$, $S E=.759, \beta=.043, p=.265)$.

\section{Mediation and moderation}

Cortisol change was not a significant predictor of depressive symptoms. Given that simple mediation requires a relationship between the mediator and the dependent variable (Baron \& Kenny, 1986), it was unlikely that any of the indirect effects of the model would be significant. Indeed, neither of the two indirect effects (i.e., 1: EM $\rightarrow$ Cort $\rightarrow$ depression; $2:$ LM $\rightarrow$ Cort $\rightarrow$ depression) were significant predictors of depressive symptoms (all $p s>.1$, reflecting lack of mediation of the relationship between maltreatment and depressive symptoms through cortisol change. Further, there was no direct effect or moderation by multigenic risk on cortisol change (main effect: $B=-.002, S E=.002, \beta=$ $-.039, p=.443$; interaction with early-onset maltreatment: $B=.000, S E=.003, \beta=-.002, p=.970$; interaction with late-onset maltreatment: $B=.005, S E=.007, \beta=.030, p=.443)$. Thus, the 


\subsection{5}

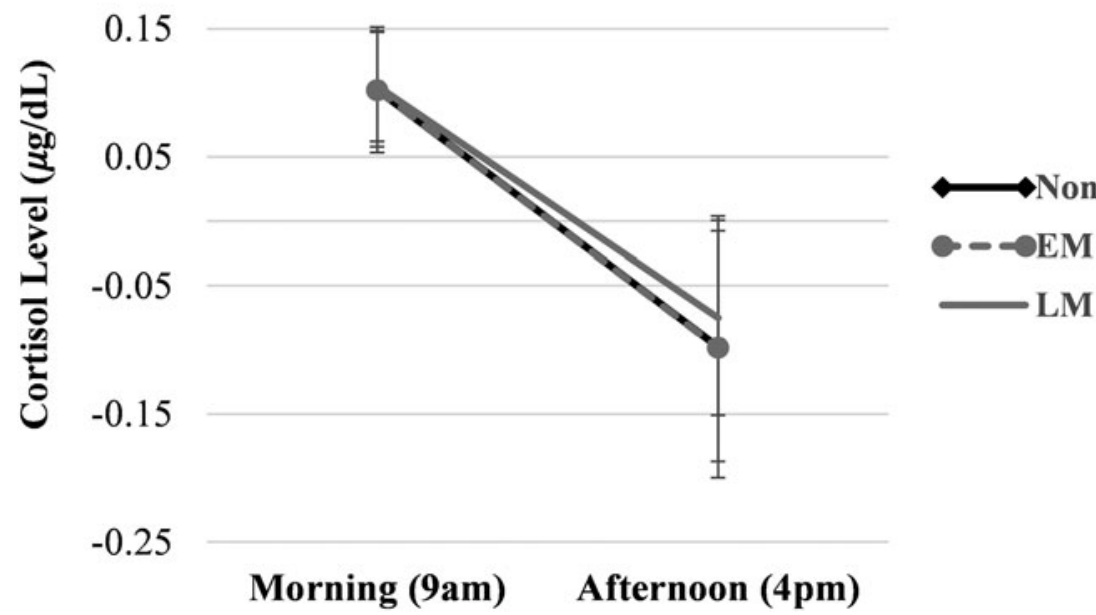

Figure 3. Cortisol change differences from morning to afternoon: Note: $\mathrm{EM}=$ early-onset maltreated; $\mathrm{LM}=$ late-onset maltreated; Non $=$ nonmaltreated. While groups did not differ significantly at either time of day, the significant difference score between groups exists in the context of a slight lowering of morning and a slight increase of afternoon cortisol levels for LM children. Error bars show 1SD.

functional, HPA axis-related SNPs included as part of the multigenic index in this study were not directly or indirectly related to daytime production of cortisol.

\section{Follow-up analyses}

\section{Depressive symptoms}

We explored mean differences in depressive symptoms to depict relative levels among the groups. As can be seen in Figure 2, early-onset maltreated children reported more depressive symptoms $(M=8.634, S D=7.368)$ than nonmaltreated children $(M=$ $6.791, S D=6.499)$. There were no differences between late-onset and nonmaltreated children or late and early-onset maltreated children.

\section{Morning and afternoon cortisol}

To better understand the nature of the cortisol change patterns found among maltreatment groups, separate linear regressions with mean morning and afternoon cortisol values as outcome variables were conducted. Maltreatment groups did not exhibit significant difference in morning $(M \mathrm{EM}=.103$, $S D=.046 ; M \mathrm{LM}=.105, S D=.043 ; M$ Non $=.103, S D=.045$; $F(2,733)=.158, p=.853)$ or afternoon $(M \quad \mathrm{EM}=-.098$, $S D=.102 ; M \mathrm{LM}=-.075, S D=.076 ; M$ Non $=-.097, S D=.090$; $F(2,732)=2.762, p=.064)$ cortisol values. Although groups did not differ significantly at either time of day, as can be seen in Figure 3, there was a slight lowering of morning and a slight increase of afternoon levels for later onset maltreated children relative to nonmaltreated youth.

\section{Severity of depressive symptoms}

In light of previous findings suggesting that cortisol functioning partially depends on severity of depressive symptoms (e.g., Cicchetti et al., 2010; Hart et al., 1996), effects of maltreatment on cortisol were examined only among children with clinically significant depressive symptom levels (i.e., CDI raw score $\geq 19$ ). Controlling for gender and age, timing of maltreatment did not predict cortisol change scores for children with clinical-level depressive symptoms $(F(2,52)=.999, p=.375)$. Additionally, timing of maltreatment did not predict differences in morning or afternoon cortisol levels for children with clinical-level depressive symptoms (morning: $F(2,53)=.062, p=.940$; afternoon: $F(2,53)=1.218, p=.304)$.

\section{Chronicity and recency of maltreatment}

Because children who had an earlier onset of maltreatment also experienced more chronic maltreatment, we compared the number of developmental periods across which maltreatment occurred between the three groups. Significant differences between the three groups were detected $(F(2,736)=780.864, p=.000)$. The number of development periods of maltreatment within the early-onset maltreated group $(M=1.810, S D=.934)$ was significantly greater than the late-onset maltreated group $(M=1.164$, $S D=.372$ ), and the late-onset maltreated group was also significantly greater than non-maltreated group $(M=.000, S D=.000)$. Results demonstrated that early-onset maltreatment also captures a greater range of chronicity in the current sample.

Based on descriptive characteristics, it was also evident that children whose maltreatment started later also experienced more recent experiences of maltreatment. Therefore, we compared the percentage of each developmental period when children received the most recent maltreatment between the early and late-onset groups. Results showed that, within the late-onset maltreatment group, most children received the most recent maltreatment during the later school age period, whereas in the early maltreatment group, most children received the most recent maltreatment during the preschool period $\left(\chi^{2}(4)=124.05, p=.000\right)$.

\section{Alternative genetic coding schemes}

Given various approaches to coding genotypes prevalent in the literature, and lack of information about meaningful differences for African Americans, six additional coding schemes were tested to examine whether these approaches altered the structural model. As such, dominant, recessive, and additive coding schemes were created whereby all genotypes included in the multigenic risk score were coded either in accordance with a dominant, recessive, or additive model. Furthermore, a new risk code was created that included only SNPs studied by Pagliaccio et al. (2014) and Starr and Huang (2019). Additionally, SNPs included only by Feurer et al. (2017) were tested. Finally, a risk score in which CRHR1 
SNPs were reverse-coded (i.e., opposite allele was considered risk) was examined. There were no significant direct or moderation effects for any of the alternative coding schemes on cortisol difference score when included in the structural model. Thus, alternative coding schemes did not account for the lack of replication.

\section{Genetic moderation of depressive symptoms}

Finally, because most previous studies have tested genetic moderation of depressive outcomes, rather than HPA functioning, we explored whether similar positive associations would emerge if focusing only on this path. However, there was no significant genetic moderation of the maltreatment-depression path, for either early-onset or late-onset maltreatment (both $p s>.1$ ). Thus, even our direct effect lacked genetic moderation and cannot support previous findings that have exclusively examined genetic moderation of depressive outcomes in maltreated children.

\section{Discussion}

The current study examined associations among maltreatment timing, multigenic risk, HPA functioning, and depressive symptoms in an effort to better understand mechanisms by which disruptions to the child-caregiver relationship negatively affect mental health in maltreated, African American children. Overall, results highlight the complexity of development, convey the concept of equifinality, and reiterate the need for future longitudinal research on this topic.

\section{Early-onset maltreatment}

Timing specificity and depressive symptoms

As hypothesized, early-onset maltreatment predicted depressive symptoms in African American youth, suggesting timedependent effects of maltreatment. Results echo findings of several earlier studies using mixed-race samples (Cicchetti et al., 2010; Hart et al.,1995; Kaplow \& Widom, 2007; Keiley et al., 2001; Manly et al., 2001). Our replication suggests that previous findings generalize to African Americans, and points toward early-onset maltreatment as being a powerful vulnerability factor for the development of depressive symptoms for diverse groups, above and beyond other forms of risk.

Of note, early-onset maltreated children in the current study experienced maltreatment across a greater number of developmental periods than later onset maltreated children. Chronic maltreatment has been considered one of the most robust predictors of general maladaptation (Manly et al., 2001), even when considering other maltreatment characteristics such as severity of maltreatment (Bolger et al., 1998). Our findings suggest that early, chronic maltreatment may be the most deleterious combination when predicting depressive symptoms, likely given the increased chances for cumulative, cascading effects across developmental periods.

Importantly, the significant relationship between early but not late-onset maltreatment and depressive symptoms in the current study does not remove the possibility that later onset maltreated children will develop depressive symptoms. Instead, it may be that both early and late-onset maltreatment affect depressive symptoms but through different pathways and on a different timeline (equifinality). Our divergent findings suggest that conceptualizing risk mechanisms for early and late-onset maltreatment separately may optimally inform intervention for these distinct groups of at-risk African American children.

\section{HPA axis functioning}

Contrary to hypotheses, HPA function did not mediate the observed relationship between early-onset maltreatment and depressive symptoms. The developmental psychopathology principle of equifinality proposes that maltreated children can travel many different pathways to the same pathological outcome (Cicchetti \& Rogosch, 1996). There are alternate pathways unexplored in the current study that may explain our results, including the attachment relationship. Attachment stabilizes between 6 to 18 months of age (e.g., Ainsworth, Blehar, Waters, \& Wall, 1978; Belsky, Rovine, \& Taylor, 1984) - the time when many of the children in the early maltreatment group first experienced maltreatment. Higher rates of depressive symptoms have been found in children with disrupted attachment (Groh, Roisman, van IJzendoorn, Bakermans-Kranenburg, \& Fearon, 2012), and improvements in attachment following intervention reduces both depressive symptoms and HPA dysfunction in maltreated kids (Bernard, Hostinar, \& Dozier, 2015; Cicchetti et al., 2011b; Dozier, Peloso, Lewis, Laurenceau, \& Levine, 2008; Ippen, Harris, Van Horn, \& Lieberman, 2011). Examining attachment as an alternate mechanism of risk transmission, particularly while considering both maltreatment timing and concurrent and prospective HPA function, will shed light on different mechanisms operating within subgroups.

Lack of mediation in the current study may also suggest that HPA dysfunction follows symptom onset (i.e., represents a "scar" of depressive symptoms). Doane et al. (2013) found that blunted diurnal slopes were evident for adolescents who had past episodes of depression but not for those whose depression onset was within 3 months of cortisol assessment. It may be that early-onset maltreated children in the current study had more recent onset of symptoms precluding any significant association between cortisol and depressive symptoms. Prospective, longitudinal assessments of symptoms are clearly needed going forward.

\section{Late-onset maltreatment}

\section{Timing specificity for HPA axis functioning}

Unexpectedly, late-onset maltreated children exhibited more disruption to the HPA axis, and this relationship was not associated with depressive symptoms. Notably, later onset maltreated children were also more likely to have experienced maltreatment recently, closer to the time of assessment. It may be that later onset maltreated children in the current study demonstrated blunted cortisol patterns because HPA effects are better captured by current adversity/context rather than early adversity. There has been speculation about whether diurnal patterns documented in the literature represent early adversity, current adversity, or both (Tarullo \& Gunnar, 2006). A previous meta-analysis supports recency effects of stress on HPA activity, demonstrating that some cortisol outcomes are more pronounced for more recently occurring stress (Miller, Chen, \& Zhou, 2007). A more recent meta-analysis supports and extends this proposal, suggesting that circadian dysregulation, specifically, is initiated and maintained by proximal stress - a term referred to as "stress-related circadian dysregulation" (SCiD) - which, over time, may evolve into a variety of mental and physical health problems (Adam et al., 2017).

Results of the current study point toward the salience of temporally proximal life stress on diurnal patterning given the following: (a) children in the current study who were maltreated earlier in life did not evince diurnal blunting, despite having more 
chronic experiences, which have also been linked to diurnal blunting (e.g., Boyce et al., 1995; McCormack et al., 2003; Starr et al., 2019 ), and (b) only a small percentage (20.0\%) of early-onset maltreated children had recent experiences of maltreatment, while a majority (63\%) of late-onset maltreated children had recent experiences of maltreatment.

\section{Lack of mediation of depressive symptoms}

There was no relationship between late-onset maltreatment and depressive symptoms. Additionally, there was no relationship between the existent cortisol dysfunction and depressive symptoms for children with later onset maltreatment. The hypothesized relevance of HPA dysfunction to the development of depressive symptoms requires speculation about why cortisol changes evident in the late-onset maltreatment group did not predict depressive symptoms.

Time sequencing may account for the lack of association between dysregulated cortisol and depressive symptoms for late-onset maltreated children. That is, the effect of cortisol disruptions may not yet have had time to behaviorally manifest. Such "sleeper" effects are plausible, given that HPA axis changes predate behavioral changes in other domains (e.g., delay in effect of psychotropic medication on behavior). Thus, it may be that for those children whose primary path toward depressive symptoms is through HPA dysfunction, the dysfunction takes time to embed. The fact that HPA dysfunction serves as a stronger prospective predictor of recurrent depressive episodes rather than first-onset episodes (Vrshek-Schallhorn et al., 2013) provides partial support for this hypothesis. However, the Vrshek-Schallhorn et al. (2013) study was conducted with high SES, low adversity samples, examined the cortisol awakening response (CAR)-a process that is distinct from diurnal rhythms-and did not consider maltreatment status. Thus, longitudinal studies of maltreatment, various forms of HPA function, and depressive symptoms would help clarify whether HPA dysfunction better reflects risk for or impact of depressive symptoms in different groups of maltreated children.

Typical rises in depressive symptoms occur during adolescence, often coinciding with the pubertal transition (Hilt \& Nolen-Hoeksema, 2014). Consequently, our null findings may be a function of the young age of our sample and low base rate of depressive disorders in earlier childhood. Similarly, pubertal status may explain our null results. Recent studies have found that pubertal development moderates the influence of HPA dysregulation on subsequent depressive symptoms in at-risk females (Colich, Kircanski, Foland-Ross, \& Gotlib, 2015). Though not assessed, our sample likely includes few pubertal youth, given that a majority $(70 \%)$ of the children were 10 -years-old or younger. Researchers have recently demonstrated that the HPA axis recalibrates during puberty, supporting the conceptualization of this developmental period as a window of opportunity, or, conversely, vulnerability, depending on the environment (Gunnar, DePasquale, Reid, \& Donzella, 2019). Because our modest HPA findings were specific to later onset maltreated children who also had more recent stress, it is possible that more obvious HPA dysregulation as well as mental health sequelae may only manifest during the pubertal transition, barring intervention. Continued study across development is warranted.

\section{Genetic risk}

Contrary to hypotheses, multigenic risk was unrelated to cortisol functioning, regardless of coding scheme utilized. It has been common in the literature to use genotype as a proxy for biological functioning, rather than directly testing gene-cortisol associations. The current study filled this gap, though no relationship was present.

There are many plausible explanations for our null genetic findings. First, risk allele classification is especially complicated in our under-studied sample of African American children for which we lack comparison for some of the genotypes. Generally, heterogeneity in measurement models is a major obstacle to replicating gene-environment associations, as it contributes to divergent classifications and lack of consensus regarding which allele constitutes risk and under what conditions (Bogdan et al., 2017). The previous studies that have informed our investigation (Pagliaccio et al., 2014; Starr \& Huang, 2019; Starr et al., 2019) differed in many respects, including type and measurement of adversity, outcome variables probed, contextual variables, and sample characteristics (developmental age, race, SES). In all studies, the sample was primarily Caucasian. Differences in maltreatment classification alone have recently been found to drastically alter associations with poor health, depending on type and specificity of maltreatment report (i.e., prospective vs. retrospective; Baldwin, Reuben, Newbury, \& Danese, 2019). Therefore, when adding heterogeneity among additional measures across studies, our understanding of risk is exponentially blurred.

Even in cases where previous studies utilized primarily African American samples, none used a multigenic risk index, and available information regarding which allele constitutes risk was often blatantly contradictory (i.e., for CRHR1 SNPs, see Bradley et al., 2008; Polanczyk et al., 2009 vs. Pagliaccio et al., 2014; Cicchetti et al., 2011a; Cicchetti \& Rogosch, 2014). To this end, we created multiple types of coding schemes, including the use of reverse-codes (whereby the opposite allele was scored as risk), yet alternate coding still did not impact outcomes. Thus, it appears that these SNPs are not operating in a functional way for this group of African American youth, at least with regard to diurnal cortisol production. It is possible that the particular genes and/or SNPs in the current study do not explicitly govern diurnal cortisol production, given that many of the SNPs have been tested with regard to stress reactivity, which is a distinct aspect of HPA function. That being said, Starr et al. (2019) did find association between some of these SNPs in a multigenic risk index and diurnal cortisol in a sample of primarily Caucasian teens.

It is alternatively possible that the associations found in previous studies relating multigenic risk to depression and/or HPA function are specific to the exact SNPs that were included in previous studies. However, in additional exploratory analyses, we included only the same four SNPs that Pagliaccio et al. (2014) and Starr et al. (2019), included and the same six SNPs that Feurer et al. (2017) included, still without significant associations. Again, discrepancy may be a function of the variability in sample characteristics, most notably, race, given poor representation of African Americans in these aforementioned studies. In any case, establishing more narrow criteria of risk strictly related to measured biological functioning in developmentally uniform and psychiatrically healthy African American samples may enhance operationalization of risk and better inform future studies of mechanistic processes in this under-represented group.

Finally, lack of moderation by multigenic risk in the current study may be more largely suggestive of poor predictive validity of the candidate gene approach. A recent study by Border et al. (2019) addressed the replication failure in psychiatric genetics. 
Using samples as large as 443,264 , these researchers found no support for candidate gene and candidate gene by environment findings for depression across various diverse samples. They argue that previous associations are likely spurious findings. This possibility cannot be ruled out based on results of the current study.

\section{Limitations}

This study is the first to examine concurrent associations among maltreatment, genetic factors, HPA axis function, and depressive symptoms in African American children in a moderated mediation model. Validated assessment of maltreatment using DHS records and use of a classification system allowing for the examination of important maltreatment parameters is an incredible advantage of this study. The sample was large, allowing for adequate power to detect effects. Additionally, the use of a multigenic index more adequately represents the biological system under study and increases statistical power. Finally, an ancestrally homogeneous sample allowed for examination of risk processes in a sorely under-studied group. Our ability to evade population stratification issues offer a more accurate picture of genetic association among African Americans.

Despite these strengths, there are limitations to consider. First, the sample, overall, was relatively normative with regard to the level of depressive symptoms and HPA axis functioning, and mean differences were generally small. Therefore, this sample may not be a highly representative sample of maltreated children, overall. Secondly, although a goal was to explore mechanisms using moderated mediation, this is a cross-sectional study and pathways simply reflect linear associations at one point in time of development. Lack of significant mediation in the current sample does not remove the possibility that mediation may emerge over time.

Additionally, it was not possible to fully represent the diurnal pattern given that samples were not collected at wake or at bedtime. Although this would have been optimal, the characteristics of this very low SES sample make home collection of salivary samples a difficult task. Thus, having a consistent collection time and storing procedure in the context of the summer camp, though not allowing for examination of the full diurnal picture, may have provided a more accurate representation than homebased assessment.

Information on wake-up time was also not obtained, precluding the possibility of controlling for this variable in analyses. Wake-up time is relevant to the daytime production pattern given that morning levels are higher after awakening due to the CAR, thus morning levels are more so related to the time a child awoke rather than the chronological time of day. As such, without controlling for time of wake, morning values used in the current study may vary as a function of a child's wake-up time rather than due to their maltreatment status. It is unlikely that this is the case, however, given that this possibility would have required the entire group of later onset maltreated children to have woken up much earlier in the day than both of the other groups.

It was also not possible to control for other factors known to influence HPA axis functioning, such as pubertal status or use of medication such as acetaminophen, oral contraceptives, and psychotropic agents. Children's cortisol levels increase during puberty (Gunnar, Wewerka, Frenn, Long, \& Griggs, 2009;
Stroud et al., 2009) and may recalibrate to the environment of the pubertal period (Gunnar et al., 2019), and medication use has been shown to affect stress hormone levels. With relevance to the current study, antipsychotics have been specifically linked to flatter diurnal rhythms in children regardless of risk status (Hibel, Granger, Cicchetti, \& Rogosch, 2007). Such agents could, thus, have introduced error variance into the current investigation and impacted results especially if more children in the late-onset maltreatment group were disproportionately utilizing antipsychotic medication or were more pubertally advanced (though this is unlikely given that most youth were age 10 or younger). Regardless, both puberty and medication use should be considered in future projects in an effort to best understand HPA function and stress-related vulnerability in African Americans.

\section{Conclusions and Future Directions}

Development involves complex, dynamic, interactive systems that cascade and shift across the lifespan. Maltreatment introduces a potent pathogen into the developmental process and can have farreaching effects. Two such implications for maltreatment on development includes depressive symptoms and alterations to the typical circadian process of the HPA axis, depending on timing of maltreatment, as revealed in the current investigation. There are numerous pathways a child may follow toward both depressive symptoms and HPA axis dysfunction and a host of complications that can follow the onset of each. Only through longitudinal studies, and continued preclinical research efforts, can a better understanding of the antecedents and consequences of depressive symptoms and diurnal disruption be attained. Such studies will help clarify the nature of development and, ultimately, could help guide interventions.

Do our null findings for genetic association and HPA mediation imply differential impact of risk factors on African American children? It is possible. To help disentangle differences in methodology and measurement explaining our findings versus true differences in risk processes for African Americans, future research should adopt prospective, longitudinal examinations of maltreatment using large, diverse racial groups beginning as early in life as possible. Critically, these designs should repeatedly assess psychiatric symptoms as well as other forms of current life stress, to serve as a reference of comparison. Additionally, repeated assessments of HPA function across time will be particularly fruitful. Probing multiple aspects of HPA functioning (i.e., diurnal patterns, CAR, reactivity to/recovery from pharmacologic challenge, and reactivity to/recovery from psychosocial challenge) at multiple time points could help clarify age- and race-related patterns associated with the different aspects of the HPA axis. Systematic, independent validation of genetic risk in African Americans will also be required. Finally, integrative models that consider the dynamic role of other proposed mediating variables at multiple levels (e.g., early attachment, peer relationships, social support, racial discrimination) will help clarify risk and protective processes involved in the development of depressive symptoms following experiences of maltreatment, and will help inform treatment and prevention of these problematic disorders in African American children.

Acknowledgments. Funding by the National Institute on Drug Abuse (R01-DA17741), The National Institute of Mental Health (R01-MH83979), 
and the Spunk Fund, Inc (to DC), as well as the National Science Foundation Graduate Research Fellowship Program (to AVZ).

\section{References}

Adam, E. K., Doane, L. D., Zinbarg, R. E., Mineka, S., Craske, M. G., \& Griffith, J. W. (2010). Prospective prediction of major depressive disorder from cortisol awakening responses in adolescence. Psychoneuroendocrinology, 35, 921931. doi:10.1016/j.psyneuen.2009.12.007

Adam, E. K., Quinn, M. E., Tavernier, R., McQuillan, M. T., Dahlke, K. A., \& Gilbert, K. E. (2017). Diurnal cortisol slopes and mental and physical health outcomes: A systematic review and meta-analysis. Psychoneuroendocrinology, 83, 25-41. doi:10.1016/j.psyneuen.2017.05.018

Ainsworth, M. D., Blehar, M. C., Waters, E., \& Wall, S. (1978). Patterns of attachment: Assessed in the strange situation and at Home. Hillsdale, NJ: Erlbaum.

Andersen, S. L., \& Teicher, M. H. (2008). Stress, sensitive periods and maturational events in adolescent depression. Trends in Neurosciences, 31, 183-191. doi:10.1016/j.tins.2008.01.004

Baldwin, J. R., Reuben, A., Newbury, J. B., \& Danese, A. (2019). Agreement between prospective and retrospective measures of childhood maltreatment: A systematic review and meta-analysis. JAMA Psychiatry, 76, 584-593. doi:10.1001/jamapsychiatry.2019.0097

Barnett, D., Manly, J. T., \& Cicchetti, D. (1993). Defining child maltreatment: The interface between policy and research. Child Abuse, Child Development, and Social Policy, 8, 7-73.

Baron, R. M., \& Kenny, D. A. (1986). The moderator-mediator variable distinction in social psychological research: Conceptual, strategic, and statistical considerations. Journal of Personality and Social Psychology, 51, 1173-1182. doi:10.1037/0022-3514.51.6.1173

Belsky, J, Rovine, M, \& Taylor, DG. (1984). Pennsylvania Infant and Family Development Project, III: The origins of individual differences in infantmother attachment: Maternal and infant contributions. Child Development, 55, 718-728.

Bernard, K., Hostinar, C. E., \& Dozier, M. (2015). Intervention effects on diurnal cortisol rhythms of Child Protective Services-referred infants in early childhood: Preschool follow-up results of a randomized clinical trial JAMA Pediatrics, 169, 112-119. doi:10.1001/jamapediatrics.2014.2369

Bertrand, K. A., Bethea, T. N., Adams-Campbell, L. L., Rosenberg, L., \& Palmer, J. R. (2016). Differential patterns of risk factors for early-onset breast cancer by ER status in African American women. Cancer Epidemiology, Biomarkers \& Prevention, 26, 270-277. doi:10.1158/ 1055-9965.EPI-16-0692

Binder, E. B., Bradley, R. G., Liu, W., Epstein, M. P., Deveau, T. C., Mercer, K. B., ... Ressler, K. J. (2008). Association of FKBP5 polymorphisms and childhood abuse with risk of posttraumatic stress disorder symptoms in adults. JAMA, 299, 1291-1305. doi:10.1001/jama.299.11.1291

Binder, E. B., Salyakina, D., Lichtner, P., Wochnik, G. M., Ising, M., Pütz, B., ... Kohli, M. A. (2004). Polymorphisms in FKBP5 are associated with increased recurrence of depressive episodes and rapid response to antidepressant treatment. Nature Genetics, 36, 1319-1325. doi:10.1038/ng1479

Birmaher, B., Dahl, R. E., Perel, J., Williamson, D. E., Nelson, B., Stull, S., ... Nguyen, N. (1996). Corticotropin-releasing hormone challenge in prepubertal major depression. Biological Psychiatry, 39, 267-277. doi:10.1016/ 0006-3223(95)00177-8

Bogdan, R., Salmeron, B. J., Carey, C. E., Agrawal, A., Calhoun, V. D., Garavan, H., ... Goldman, D. (2017). Imaging genetics and genomics in psychiatry: A critical review of progress and potential. Biological Psychiatry, 82, 165-175. doi:10.1016/j.biopsych.2016.12.030

Bogdan, R., Williamson, D. E., \& Hariri, A. R. (2012). Mineralocorticoid receptor Iso/Val (rs5522) genotype moderates the association between previous childhood emotional neglect and amygdala reactivity. American Journal of Psychiatry, 169, 515-522. doi:10.1176/appi.ajp.2011.11060855

Bolger, K. E., Patterson, C. J., \& Kupersmidt, J. B. (1998). Peer relationships and self-esteem among children who have been maltreated. Child Development, 69, 1171-1197. doi:10.1111/j.1467-8624.1998.tb06166.x
Border, R., Johnson, E. C., Evans, L. M., Smolen, A., Berley, N., Sullivan, P. F., \& Keller, M. C. (2019). No support for historical candidate gene or candidate gene-by-interaction hypotheses for major depression across multiple large samples. American Journal of Psychiatry, 176, 376-387. doi:10.1176/ appi.ajp.2018.18070881

Boyce, W. T., Chesney, M., Alkon, A., Tschann, J. M., Adams, S., Chesterman, B., ... Wara, D. (1995). Psychobiologic reactivity to stress and childhood respiratory illnesses: Results of two prospective studies. Psychosomatic Medicine, 57, 411-422.

Bradley, R. G., Binder, E. B., Epstein, M. P., Tang, Y., Nair, H. P., Liu, W., ... Newport, D. J. (2008). Influence of child abuse on adult depression: moderation by the corticotropin-releasing hormone receptor gene. Archives of General Psychiatry, 65, 190-200. doi:10.1001/archgenpsychiatry.2007.26

Brody, G. H., Chen, Y.-F., Murry, V. M., Ge, X., Simons, R. L., Gibbons, F. X., ... Cutrona, C. E. (2006). Perceived discrimination and the adjustment of African American youths: A five-year longitudinal analysis with contextual moderation effects. Child Development, 77, 1170-1189. doi:10.1111/ j.1467-8624.2006.00927.x

Cicchetti, D., \& Barnett, D. (1991). Toward the development of a scientific nosology of child maltreatment. In W. Grove \& D. Cicchetti (Eds.), Thinking clearly about psychology: Essays in honor of Paul E. Meehl: Personality and psychopathology (Vol. 2, pp. 346-377). Minneapolis, MN: University of Minnesota Press.

Cicchetti, D., \& Lynch, M. (1995). Failures in the expectable environment and their impact on individual development: The case of child maltreatment. In D. Cicchetti \& D. J. Cohen (Eds.), Developmental psychopathology: Risk, disorder, and adaptation (Vol. 2, pp. 32-71). New York: John Wiley \& Sons.

Cicchetti, D., \& Manly, J. T. (1990). A personal perspective on conducting research with maltreating families: Problems and solutions. Methods of Family Research: Families at Risk, 2, 87-133.

Cicchetti, D., \& Rogosch, F. A. (1996). Equifinality and multifinality in developmental psychopathology. Development and Psychopathology, 8, 597-600. doi:10.1017/S0954579400007318

Cicchetti, D., \& Rogosch, F. A. (2001). The impact of child maltreatment and psychopathology on neuroendocrine functioning. Development and Psychopathology, 13, 783-804. doi:10.1017/S0954579401004035

Cicchetti, D., \& Rogosch, F. A. (2014). Genetic moderation of child maltreatment effects on depression and internalizing symptoms by serotonin transporter linked polymorphic region (5-HTTLPR), brain-derived neurotrophic factor (BDNF), norepinephrine transporter (NET), and corticotropin releasing hormone receptor 1 (CRHR1) genes in African American children. Development and Psychopathology, 26, 1219-1239. doi:10.1017/ S0954579414000984

Cicchetti, D., Rogosch, F. A., Gunnar, M. R., \& Toth, S. L. (2010). The differential impacts of early physical and sexual abuse and internalizing problems on daytime cortisol rhythm in school-aged children. Child Development, 81 , 252-269. doi:10.1111/j.1467-8624.2009.01393.x

Cicchetti, D., Rogosch, F. A., \& Oshri, A. (2011a). Interactive effects of corticotropin releasing hormone receptor 1 , serotonin transporter linked polymorphic region, and child maltreatment on diurnal cortisol regulation and internalizing symptomatology. Development and Psychopathology, 23, 1125-1138. doi:10.1017/S0954579411000599

Cicchetti, D., Rogosch, F. A., Toth, S. L., \& Sturge-Apple, M. L. (2011b). Normalizing the development of cortisol regulation in maltreated infants through preventive interventions. Development and Psychopathology, 23, 789-800. doi:10.1017/S0954579411000307

Cicchetti, D., \& Toth, S. L. (2015). Child Maltreatment. In M. Lamb (Ed.), Handbook of child psychology and developmental science, 7th ed., Vol. 3: Socioemotional process (pp. 513-63). New York: Wiley.

Cicchetti, D., Toth, S., \& Manly, J. (2003). Maternal maltreatment interview. Rochester, NY: Mt. Hope Family Center. Unpublished manuscript.

Clark, D. G., Boan, A. D., Sims-Robinson, C., Adams, R. J., Amella, E. J., Benitez, A., ... Ovbiagele, B. (2018). Differential impact of index stroke on dementia risk in African-Americans compared to whites. Journal of Stroke and Cerebrovascular Diseases, 27, 2725-2730. doi:10.1016/ j.jstrokecerebrovasdis.2018.05.048

Colich, N. L., Kircanski, K., Foland-Ross, L. C., \& Gotlib, I. H. (2015). HPA-axis reactivity interacts with stage of pubertal development to predict 
the onset of depression. Psychoneuroendocrinology, 55, 94-101. doi:10.1016/ j.psyneuen.2015.02.004

Dackis, M. N., Rogosch, F. A., Oshri, A., \& Cicchetti, D. (2012). The role of limbic system irritability in linking history of childhood maltreatment and psychiatric outcomes in low-income, high-risk women: Moderation by FK506 binding protein 5 haplotype. Development and Psychopathology, 24, 1237-1252. doi:10.1017/S0954579412000673

De Los Reyes, A., \& Kazdin, A. E. (2005). Informant discrepancies in the assessment of childhood psychopathology: A critical review, theoretical framework, and recommendations for further study. Psychological Bulletin, 131, 483-509. doi:10.1037/0033-2909.131.4.483

Dick, D. M., Agrawal, A., Keller, M. C., Adkins, A., Aliev, F., Monroe, S., ... Sher, K. J. (2015). Candidate Gene-Environment interaction research: Reflections and recommendations. Perspectives on Psychological Science, 10, 37-59. doi:10.1177/2F1745691614556682

Di Iorio, C. R., Carey, C. E., Michalski, L. J., Corral-Frias, N. S., Conley, E. D., Hariri, A. R., \& Bogdan, R. (2017). Hypothalamic-pituitary-adrenal axis genetic variation and early stress moderates amygdala function. Psychoneuroendocrinology, 80, 170-178. doi:10.1016/j.psyneuen.2017.03.016

Doane, L. D., Mineka, S., Zinbarg, R. E., Craske, M., Griffith, J. W., \& Adam, E. K. (2013). Are flatter diurnal cortisol rhythms associated with major depression and anxiety disorders in late adolescence? The role of life stress and daily negative emotion. Development and Psychopathology, 25, 629-642. doi:10.1017/S0954579413000060

Dozier, M., Peloso, E., Lewis, E., Laurenceau, J.-P., \& Levine, S. (2008). Effects of an attachment-based intervention on the cortisol production of infants and toddlers in foster care. Development and Psychopathology, 20, 845859. doi:10.1017/S0954579408000400

English, D. J., Upadhyaya, M. P., Litrownik, A. J., Marshall, J. M., Runyan, D. K., Graham, J. C., \& Dubowitz, H. (2005). Maltreatment's wake: The relationship of maltreatment dimensions to child outcomes. Child Abuse and Neglect, 29, 597-619. doi:10.1016/j.chiabu.2004.12.008

Feder, A., Coplan, J. D., Goetz, R. R., Mathew, S. J., Pine, D. S., Dahl, R. E., ... Weissman, M. M. (2004). Twenty-four-hour cortisol secretion patterns in prepubertal children with anxiety or depressive disorders. Biological Psychiatry, 56, 198-204. doi:10.1016/j.biopsych.2004.05.005

Feurer, C., McGeary, J. E., Knopik, V. S., Brick, L. A., Palmer, R. H., \& Gibb, B. E. (2017). HPA axis multilocus genetic profile score moderates the impact of interpersonal stress on prospective increases in depressive symptoms for offspring of depressed mothers. Journal of Abnormal Psychology, 126, 10171028. doi:10.1037/abn0000316

Fombonne, E., Wostear, G., Cooper, V., Harrington, R., \& Rutter, M. (2001). The Maudsley long-term follow-up of child and adolescent depression. The British Journal of Psychiatry, 179, 210-217. doi:10.1192/bjp.179.3.210

González, H. M., Vega, W. A., Williams, D. R., Tarraf, W., West, B. T., \& Neighbors, H. W. (2010). Depression care in the United States: too little for too few. Archives of General Psychiatry, 67, 37-46. doi:10.1001/ archgenpsychiatry.2009.168

Groh, A. M., Roisman, G. I., van IJzendoorn, M. H., Bakermans-Kranenburg, M. J., \& Fearon, R. (2012). The significance of insecure and disorganized attachment for children's internalizing symptoms: A meta-analytic study. Child Development, 83, 591-610. doi:10.1111/j.1467-8624.2011.01711.x

Gunnar, M. R., DePasquale, C. E., Reid, B. M., \& Donzella, B. (2019). Pubertal stress recalibration reverses the effects of early life stress in postinstitutionalized children. PNAS, 116, 23984-23988. doi:10.1073/pnas.1909699116

Gunnar, M. R., Wewerka, S., Frenn, K., Long, J. D., \& Griggs, C. (2009). Developmental changes in hypothalamus-pituitary-adrenal activity over the transition to adolescence: normative changes and associations with puberty. Development and Psychopathology, 21, 69-85. doi:10.1017/ S0954579409000054

Halligan, S. L., Herbert, J., Goodyer, I., \& Murray, L. (2007). Disturbances in morning cortisol secretion in association with maternal postnatal depression predict subsequent depressive symptomatology in adolescents. Biological Psychiatry, 62, 40-46. doi:10.1016/j.biopsych.2006.09.011

Halligan, S. L., Herbert, J., Goodyer, I. M., \& Murray, L. (2004). Exposure to postnatal depression predicts elevated cortisol in adolescent offspring. Biological Psychiatry, 55, 376-381. doi:10.1016/j.biopsych.2003.09.013
Hammen, C. (2005). Stress and depression. Annual Review of Clinical Psychology, 1, 293-319. doi:10.1146/annurev.clinpsy.1.102803.143938

Hart, J., Gunnar, M., \& Cicchetti, D. (1995). Salivary cortisol in maltreated children: Evidence of relations between neuroendocrine activity and social competence. Development and Psychopathology, 7, 11-26. doi:10.1017/ S0954579400006313

Hart, J., Gunnar, M., \& Cicchetti, D. (1996). Altered neuroendocrine activity in maltreated children related to symptoms of depression. Development and Psychopathology, 8, 201-214. doi:10.1017/S0954579400007045

Heim, C., \& Binder, E. B. (2012). Current research trends in early life stress and depression: Review of human studies on sensitive periods, gene-environment interactions, and epigenetics. Experimental Neurology, 233, 102111. doi:10.1016/j.expneurol.2011.10.032

Heim, C., Mletzko, T., Purselle, D., Musselman, D. L., \& Nemeroff, C. B. (2008). The dexamethasone/corticotropin-releasing factor test in men with major depression: role of childhood trauma. Biological Psychiatry, 63, 398-405. doi:10.1016/j.biopsych.2007.07.002

Heim, C., Newport, D. J., Bonsall, R., Miller, A. H., \& Nemeroff, C. B. (2001) Altered pituitary-adrenal axis responses to provocative challenge tests in adult survivors of childhood abuse. American Journal of Psychiatry, 158 575-581. doi:10.1176/appi.ajp.158.4.575

Heim, C., Newport, D. J., Heit, S., Graham, Y. P., Wilcox, M., Bonsall, R., ... Nemeroff, C. B. (2000). Pituitary-adrenal and autonomic responses to stress in women after sexual and physical abuse in childhood. JAMA, 284, 592597. doi:10.1001/jama.284.5.592

Hibel, L. C., Granger, D. A., Cicchetti, D., \& Rogosch, F. (2007). Salivary biomarker levels and diurnal variation: associations with medications prescribed to control children's problem behavior. Child Development, 78, 927-937. doi:10.1111/j.1467-8624.2007.01041.x

Hilt, L. M., \& Nolen-Hoeksema, S. (2014). Gender differences in depression. In I. H. Gotlib \& C. L. Hammen (Eds.), Handbook of depression (3rd ed., pp. 355-373). New York: The Guildford Press.

Hu, L. t., \& Bentler, P. M. (1999). Cutoff criteria for fit indexes in covariance structure analysis: Conventional criteria versus new alternatives. Structural Equation Modeling: A Multidisciplinary Journal, 6, 1-55. doi:10.1080/ 10705519909540118

Ippen, C. G., Harris, W. W., Van Horn, P., \& Lieberman, A. F. (2011). Traumatic and stressful events in early childhood: Can treatment help those at highest risk? Child Abuse and Neglect, 35, 504-513. doi:10.1016/ j.chiabu.2011.03.009

Kaplow, J. B., \& Widom, C. S. (2007). Age of onset of child maltreatment predicts long-term mental health outcomes. Journal of Abnormal Psychology, 116, 176-187. doi:10.1037/0021-843X.116.1.176

Keiley, M. K., Howe, T. R., Dodge, K. A., Bates, J. E., \& Pettit, G. S. (2001) The timing of child physical maltreatment: A cross-domain growth analysis of impact on adolescent externalizing and internalizing problems. Development and Psychopathology, 13, 891-912. doi:10.1017/ S0954579401004084

Kendler, K. S., Karkowski, L. M., \& Prescott, C. A. (1999). Causal relationship between stressful life events and the onset of major depression. American Journal of Psychiatry, 156, 837-841. doi:10.1176/ajp.156.6.837

Kessler, R. C. (2012). The costs of depression. The Psychiatric Clinics of North America, 35, 1-14. doi:10.1016/j.psc.2011.11.005

Kim, J., \& Cicchetti, D. (2006). Longitudinal trajectories of self-system processes and depressive symptoms among maltreated and nonmaltreated children. Child Development, 77, 624-639. doi:10.1111/j.1467-8624.2006. 00894.x

Koss, K. J., Cummings, E. M., Davies, P. T., \& Cicchetti, D. (2017). Patterns of adolescent regulatory responses during family conflict and mental health trajectories. Journal of Research on Adolescence, 27, 229-254. doi:10.1111/ jora. 12269

Koss, K. J., \& Gunnar, M. R. (2018). Annual Research Review: Early adversity, the HPA axis, and child psychopathology. Journal of Child Psychology and Psychiatry, 59, 327-346. doi:10.1111/jcpp.12784

Kovacs, M. (1982, 1992). The children's depression inventory: A self-rated depression scale for school-aged youngsters. Pittsburgh, PA: University of Pittsburgh. 
Kuhlman, K. R., Chiang, J. J., Horn, S., \& Bower, J. E. (2017). Developmental psychoneuroendocrine and psychoneuroimmune pathways from childhood adversity to disease. Neuroscience and Biobehavioral Reviews, 80, 166-184. doi:10.1016/j.neubiorev.2017.05.020

Liu, Z., Zhu, F., Wang, G., Xiao, Z., Wang, H., Tang, J., .. Cao, Z. (2006). Association of corticotropin-releasing hormone receptor1 gene SNP and haplotype with major depression. Neuroscience Letters, 404, 358-362. doi:10.1016/j.neulet.2006.06.016

Lopez-Duran, N. L., Kovacs, M., \& George, C. J. (2009). Hypothalamicpituitary-adrenal axis dysregulation in depressed children and adolescents: A meta-analysis. Psychoneuroendocrinology, 34, 1272-1283. doi:10.1016/ j.psyneuen.2009.03.016

Manly, J. T., Kim, J. E., Rogosch, F. A., \& Cicchetti, D. (2001). Dimensions of child maltreatment and children's adjustment: Contributions of developmental timing and subtype. Development and Psychopathology, 13, 759782. doi:10.1017/S0954579401004023

McCormack, K., Grand, A., LaPrairie, J., Fulks, R., Graff, A., Maestripieri, D., ... Sanchez, M. M. (2003). Behavioral and neuroendocrine outcomes of infant maltreatment in rhesus monkeys: The first four months. Social Neuroscience, 641, 14.

Miller, G. E., Chen, E., \& Zhou, E. S. (2007). If it goes up, must it come down? Chronic stress and the hypothalamic-pituitary-adrenocortical axis in humans. Psychological Bulletin, 133, 25-45.

Muthén, L. K., \& Muthén, B. O. (1998-2017). Mplus User's Guide (8th ed.). Los Angeles, CA: Muthén \& Muthén.

Nanni, V., Uher, R., \& Danese, A. (2012). Childhood maltreatment predicts unfavorable course of illness and treatment outcome in depression: A metaanalysis. American Journal of Psychiatry, 169, 141-151. doi:10.1176/ appi.ajp.2011.11020335

Nestler, E. J., Barrot, M., DiLeone, R. J., Eisch, A. J., Gold, S. J., \& Monteggia, L. M. (2002). Neurobiology of depression. Neuron, 34, 13-25. doi:10.1016/ S0896-6273(02)00653-0

Odgerel, Z., Talati, A., Hamilton, S. P., Levinson, D. F., \& Weissman, M. M. (2013). Genotyping serotonin transporter polymorphisms 5-HTTLPR and rs25531 in European- and African-American subjects from the National Institute of Mental Health's Collaborative Center for Genomic Studies. Translational Psychiatry, 3, 1-6. doi:10.1038/tp.2013.80

O’Neal, W. T., Judd, S. E., Limdi, N. A., McIntyre, W. F., Kleindorfer, D. O., Cushman, M., ... Soliman, E. Z. (2017). Differential impact of risk factors in Blacks and Whites in the development of atrial fibrillation: The REasons for Geographic And Racial Differences in Stroke (REGARDS) study. Journal of Racial and Ethnic Health Disparities, 4, 718-724. doi:10.1007/ s40615-016-0275-3

Ouellet-Morin, I., Robitaille, M., Langevin, S., Cantave, C., Brendgen, M., \& Lupien, S. J. (2019). Enduring effect of childhood maltreatment on cortisol and heart rate responses to stress: The moderating role of severity of experiences. Development and Psychopathology, 31, 497-508. doi:10.1017/ S0954579418000123

Pagliaccio, D., Luby, J. L., Bogdan, R., Agrawal, A., Gaffrey, M. S., Belden, A. C., ... Barch, D. M. (2014). Stress-system genes and life stress predict cortisol levels and amygdala and hippocampal volumes in children. Neuropsychopharmacology, 39, 1245-1253. doi:10.1038/npp.2013.327

Pechtel, P., \& Pizzagalli, D. A. (2011). Effects of early life stress on cognitive and affective function: An integrated review of human literature. Psychopharmacology, 214, 55-70. doi:10.1007/s00213-010-2009-2

Polanczyk, G., Caspi, A., Williams, B., Price, T. S., Danese, A., Sugden, K., ... Moffitt, T. E. (2009). Protective effect of CRHR1 gene variants on the development of adult depression following childhood maltreatment: Replication and extension. Archives of General Psychiatry, 66, 978-985. doi:10.1001/ archgenpsychiatry.2009.114

Reynold, W. M., Anderson, G., \& Bartell, N. (1985). Measuring depression in children: A multimethod assessment investigation. Journal of Abnormal Child Psychology, 13, 513-526. doi:10.1007/BF00923138

Rice, D. P., \& Miller, L. S. (1995). The economic burden of affective disorders. The British Journal of Psychiatry Supplement, 27, 34-42. doi:10.1192/ S0007125000293380

Saridjan, N. S., Velders, F. P., Jaddoe, V. W. V., Hofman, A., Verhulst, F. C., \& Tiemeier, H. (2014). The longitudinal association of the diurnal cortisol rhythm with internalizing and externalizing problems in preschoolers. The Generation R Study. Psychoneuroendocrinology, 50, 118-129. doi:10.1016/j.psyneuen.2014.08.008

Starr, L. R., Dienes, K., Li, I., \& Shaw, Z. A. (2019). Chronic stress exposure, diurnal cortisol slope, and implications for mood and fatigue: Moderation by multilocus HPA-Axis genetic variation. Psychoneuroendocrinology, 100, 156-163. doi:10.1016/j.psyneuen.2018.10.003

Starr, L. R., \& Huang, M. (2019). HPA-axis multilocus genetic variation moderates associations between environmental stress and depressive symptoms among adolescents. Development and Psychopathology, 31, 1339-1352. doi: $10.1017 /$ S0954579418000779

Stroud, L. R., Foster, E., Papandonatos, G. D., Handwerger, K., Granger, D. A., Kivlighan, K. T., \& Niaura, R. (2009). Stress response and the adolescent transition: Performance versus peer rejection stressors. Development and Psychopathology, 21, 47-68. doi:10.1017/S0954579409000042

Tarullo, A. R., \& Gunnar, M. R. (2006). Child maltreatment and the developing HPA axis. Hormones and Behavior, 50, 632-639. doi:10.1016/ j.yhbeh.2006.06.010

Thompson, R. A., \& Nelson, C. A. (2001). Developmental science and the media: Early brain development. American Psychologist, 56, 5-15. doi:10.1037/0003-066X.56.1.5

Turner, S., Armstrong, L. L., Bradford, Y., Carlson, C. S., Crawford, D. C., Crenshaw, A. T., ... Hayes, G. (2011). Quality control procedures for genome-wide association studies. Current Protocols in Human Genetics, 68, 1.19.1-1.19.18. doi: 10.1002/0471142905.hg0119s68.

Tyrka, AR, Price, LH, Gelernter, J, Schepker, C, Anderson, GM, \& Carpenter, LL. (2009). Interaction of childhood maltreatment with the corticotropinreleasing hormone receptor gene: Effects on hypothalamic-pituitary-adrenal axis reactivity. Biological Psychiatry, 66, 681-685. doi: 10.1016/j.biopsych. 2009.05.012

Vilhjálmsson, B. J., Yang, J., Finucane, H. K., Gusev, A., Lindström, S., Ripke, S., ... Do, R. (2015). Modeling linkage disequilibrium increases accuracy of polygenic risk scores. The American Journal of Human Genetics, 97, 576592. doi:10.1016/j.ajhg.2015.09.001

Vrshek-Schallhorn, S., Doane, L., Mineka, S., Zinbarg, R., Craske, M., \& Adam, E. (2013). The cortisol awakening response predicts major depression: predictive stability over a 4-year follow-up and effect of depression history. Psychological Medicine, 43, 483-493. doi:10.1017/ S0033291712001213

Warnecke, R., Oh, A., Breen, N., Gehlert, S., Paskett, E., Tucker, K., ... Hiatt, R. (2008). Approaching health disparities from a population perspective: The National Institutes of Health Centers for Population Health and Health Disparities. American Journal of Public Health, 98, 1608-1615. doi:10.2105/AJPH.2006.102525

Weaver, I. C., Cervoni, N., Champagne, F. A., D’Alessio, A. C., Sharma, S., Seckl, J. R., ... Meaney, M. J. (2004). Epigenetic programming by maternal behavior. Nature Neuroscience, 7, 847-854. doi:10.1038/nn1276

Widom, C. S., DuMont, K., \& Czaja, S. J. (2007). A prospective investigation of major depressive disorder and co-morbidity in abused and neglected grown up children (grown up). Archives of General Psychiatry, 64, 49-56. doi:10.1001/archpsyc.64.1.49

Williams, D. R., Gonzalez, H. M., Neighbors, H., Nesse, R., Abelson, J. M., Sweetman, J., \& Jackson, J. S. (2007). Prevalence and distribution of major depressive disorder in African Americans, Caribbean Blacks, and Non-Hispanic Whites. Archives of General Psychiatry, 64, 305-315. doi:10.1001/archpsyc.64.3.305

Wulsin, L. R., \& Singal, B. M. (2003). Do depressive symptoms increase the risk for the onset of coronary disease? A systematic quantitative review. Psychosomatic Medicine, 65, 201-210. doi:10.1097/01.PSY.0000058371. 50240.E3

Wüst, S., Van Rossum, E. F., Federenko, I. S., Koper, J. W., Kumsta, R., \& Hellhammer, D. H. (2004). Common polymorphisms in the glucocorticoid receptor gene are associated with adrenocortical responses to psychosocial stress. The Journal of Clinical Endocrinology \& Metabolism, 89, 565-573. doi:10.1210/jc.2003-031148

Zannas, A., \& Binder, E. (2014). Gene-environment interactions at the FKBP5 locus: Sensitive periods, mechanisms and pleiotropism. Genes, Brain and Behavior, 13, 25-37. doi:10.1111/gbb.12104 